TI 2017-104/VIII

Tinbergen Institute Discussion Paper

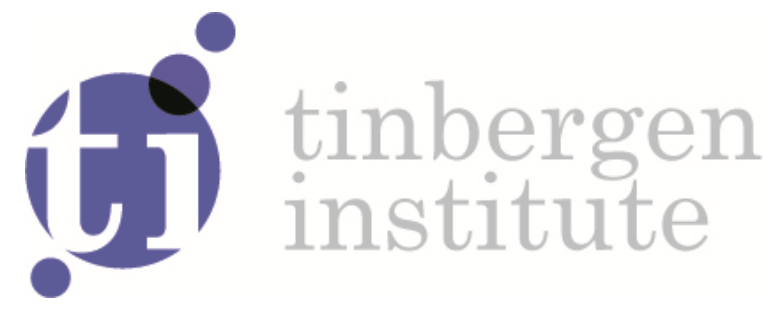

\title{
OPEC, Shale Oil, and Global Warming - On the importance of the order of extraction
}

Hassan Benchekroun ${ }^{1}$

Gerard (G.C.) van der Meijden²

Cees Withagen ${ }^{3}$

1: McGill University, CIREQ

2: Vrije Universiteit Amsterdam; Tinbergen Institute, The Netherlands

3: IPAG Business School (Paris), Vrije Universiteit Amsterdam, Tinbergen Institute 
Tinbergen Institute is the graduate school and research institute in economics of Erasmus University Rotterdam, the University of Amsterdam and VU University Amsterdam.

Contact: discussionpapers@tinbergen.nl

More TI discussion papers can be downloaded at the Tinbergen Site

Tinbergen Institute has two locations:

Tinbergen Institute Amsterdam

Gustav Mahlerplein 117

1082 MS Amsterdam

The Netherlands

Tel.: +31(0)20 5984580

Tinbergen Institute Rotterdam

Burg. Oudlaan 50

3062 PA Rotterdam

The Netherlands

Tel.: +31(0)10408 8900 


\title{
OPEC, Shale Oil, and Global Warming* On the importance of the order of extraction
}

\author{
Hassan Benchekroun \\ McGill University \\ CIREQ \\ Gerard van der Meijden $\sharp$ \\ Vrije Universiteit Amsterdam \\ Tinbergen Institute \\ Cees Withagen \\ IPAG Business School (Paris) \\ Vrije Universiteit Amsterdam \\ Tinbergen Institute
}

October 31, 2017

\begin{abstract}
We show that OPEC's market power contributes to global warming by enabling producers of relatively expensive and dirty oil to start producing before OPEC reserves are depleted. We fully characterize the equilibrium of a cartel-fringe model and use a calibration to examine the importance of this extraction sequence effect. While welfare under the cartel-fringe equilibrium can be significantly lower than under a first-best outcome, almost all of this welfare loss is due to the sequence effect. Moreover, the recent boom in shale oil reserves may reduce social welfare and renewables subsidies can increase the carbon content of current extraction.
\end{abstract}

JEL codes: Q31, Q42, Q54, Q58

Keywords: cartel-fringe, climate policy, non-renewable resource, Herfindahl rule, limit pricing

${ }^{*}$ The authors would like to thank Corrado Di Maria, Chuck Mason, Andrew Leach, Florian Leblanc, Rick van der Ploeg, Steve Salant, and participants at the Sinergia workshop (Morzine, January 2017), the Ecole Polytechnique Economics seminar (Paris, March 2017), the Eureka seminar (Amsterdam, March 2017), the WCNRM (Barcelona, June 2017), the EAERE conference (Athens, June 2017), the IRMBAM-2017 (July 2017, Nice), the FAERE annual conference (Nancy, September 2017), the BIOECON conference (September 2017, Tilburg), the CESifo Conference (October 2017, Munich), the Conference in honour of John Hartwick (October 2017, Kingston, Ontario), and the Workshop in memory of Pierre Lasserre (October 2017, Montréal, Québec) for their valuable comments. Hassan Benchekroun thanks the Fonds de recherche du Québec - Société et culture (FRQSC) and the Canadian Social Sciences and Humanities Research Council (SSHRC) for financial support. Cees Withagen and Gerard van der Meijden gratefully acknowledge financial support from FP7-IDEAS-ERC Grant No. 269788.

${ }^{\sharp}$ Corresponding author: Department of Spatial Economics, Vrije Universiteit Amsterdam, De Boelelaan 1105, 1081 HV Amsterdam, The Netherlands, Phone: +31-20-598-2840, e-mail: g.c.vander.meijden@vu.nl. 


\section{Introduction}

What is the impact of imperfect competition in the oil market on global warming? This question is relevant given the sizable carbon footprint of oil and the prominent size of OPEC. Indeed, oil is responsible for close to a quarter of anthropogenic carbon emissions (IEA, 2016) ${ }^{1}$ and, with OPEC producing 40 percent of global oil supply and owning 70 percent of world oil reserves (EIA, 2017a), it is not realistic to assume that OPEC is a price taker in the market of oil.

An old adage says that "the monopolist is the conservationist's best friend" (e.g., Dasgupta and Heal, 1979, p. 329). Indeed, we know from non-renewable resource economics that market power typically leads to higher initial resource prices and slower resource depletion. However, in the case of oil, the consequences of imperfect competition for the Earth's climate are more complex because different types of oil reserves with varying carbon contents are exploited. The reason is that imperfect competition does not only affect the speed, but also the order of extraction of different reserves of oil (cf. Benchekroun et al., 2009, 2010). Technically recoverable reserves and production of unconventional types of oil by non-OPEC countries have grown significantly over the last decade. The supply of oil sands from Canada has more than doubled, and shale oil production in the US has increased more than tenfold since 2007 (CAPP, 2017b; EIA, 2017a). Current recoverable reserves of Canadian oil sands and of US shale oil amount to 165 and 78.2 billion barrels, respectively (CAPP, 2017a; EIA, 2017b). In this paper we examine these two important features of the oil market (imperfect competition and the presence of a fringe with substantial reserves) and their implications for global warming and welfare when the damage caused by the accumulation of carbon emissions is taken into account.

Our paper is related to three strands of literature, the first one studying resource use under imperfect competition. We model the oil market as a situation where supply comes from a cartel and a large group of price-taking fringe members. ${ }^{2}$ Important contributions to the field of imperfect competition on non-renewable resource markets were made by Stiglitz (1976) on monopoly, Lewis and Schmalensee (1980) on oligopoly, Gilbert (1978) and Newbery (1981) on dominant firms. More recently, Groot

\footnotetext{
${ }^{1}$ The other important fossil fuels that contribute to anthropogenic carbon emissions are coal with 28 percent and gas with 12 percent (IEA, 2016).

${ }^{2}$ While we follow a large strand of the literature and consider that OPEC acts as a cohesive cartel (see Withagen (2013) for a survey), there is recent empirical evidence for imperfect cartelization of OPEC (cf. Almoguera et al., 2011; Brémond et al., 2012; Kisswani, 2016; Okullo and Reynès, 2016). Following the suggestion of Brémond et al. (2012) we have also examined the case where OPEC consists of two subgroups acting as Cournot duopolists. The qualitative nature of the equilibrium and the policy implications remain unchanged. We have therefore opted to keep the assumption of a cohesive cartel for the ease of exposition and economy of notation.
} 
et al. (2003), Benchekroun et al. (2009, 2010) and Benchekroun and Withagen (2012) have developed cartel-fringe models of the resource market. See also Withagen (2013) for a survey and the references therein. In the present paper we offer new insights in several respects. We take account of the existence of renewables that provide perfect substitutes for oil and that can be produced in unlimited amounts. This opens the possibility of a limit-pricing strategy by oil suppliers in equilibrium (see, e.g., Van der Meijden et al. (2015); Andrade de Sá and Daubanes (2016) and Van der Meijden and Withagen (2016) for recent work and Hoel (1978), Salant (1979) and Gilbert and Goldman (1978) for early contributions). Furthermore, we investigate the effect of climate change policies on the extraction paths as well as on welfare, allowing for damages from the accumulation of greenhouse gases.

Second, our article relates to the literature on the sequence of extraction of multiple non-renewable resource deposits with different unit extraction costs. Herfindahl (1967) and Solow and Wan (1976) show that these deposits are optimally extracted in order of increasing marginal extraction costs. The principle of extracting cheap resources before the more expensive ones has become known as the Herfindahl rule. Over the last decades, several refinements of this rule were proposed. Kemp and Long (1980) show that in general equilibrium, the Herfindahl rule may break down due to a consumption smoothing motive. Other reasons for deviations from the Herfindahl rule are heterogeneous resource demand (Chakravorty and Krulce, 1994), extraction capacity constraints (Amigues et al., 1998; Holland, 2003), upper bounds on pollution stocks (Chakravorty et al., 2008) and supply cost uncertainty (Gaudet and Lasserre, 2011). We contribute to this literature by examining how a violation of the Herfindahl rule due to imperfect competition affects global warming through the timing of carbon emissions.

The third field of research to which our study relates is the Green Paradox literature (cf. Sinclair, 1994; Sinn, 2008, 2012; Van der Ploeg and Withagen, 2015), in which it is shown that under perfect competition the announcement of stringent future climate policies (such as carbon taxes or subsidies for renewable energy) may cause an increase in current oil supply and therefore leads to an acceleration rather than a mitigation of global warming. We add to this active research field by demonstrating that, due to imperfect competition on the oil market, climate policies not only affect the level of current oil use, but also the mix between relatively clean and dirty oil. This provides an additional channel through which 'gradually greening policies' may increase current carbon emissions.

We establish the existence of a cartel-fringe equilibrium on the oil market. We fully characterize the equilibrium and perform a sensitivity analysis for different policy mea- 
sures and competitiveness indicators. The analysis takes into account that conventional oil supplied by OPEC has lower marginal extraction costs and is relatively cleaner than oil from deep-water drilling, oil sands, oil shale, and shale oil supplied by the fringe (Malins et al., 2014; Fischer and Salant, 2017; OCI, 2017). Our main findings are as follows.

First, the cartel and the fringe start out supplying simultaneously, despite their differing unit extraction costs. If the initial stock of the fringe is large relative to the cartel's, the phase with simultaneous supply will be followed by a phase during which only the fringe is active (and the stock of the cartel is depleted). In this case, there will be no limit-pricing behaviour. However, if the initial stock of the cartel is relatively large, the phase with simultaneous supply will be followed by a period during which only the cartel is supplying. During this period, the cartel either chooses to price strictly below the price of renewables, in which case the price increases over time, or to perform a limit-pricing strategy of marginally undercutting the renewables price, in which case the price is constant over time. If marginal profits in a limit-pricing regime are nonpositive, the cartel will start with limit pricing as soon as the fringe's stock is depleted. However, if marginal profits at limit pricing are positive, the cartel will only start limit pricing after the fringe's stock is depleted and its own remaining stock is smaller than a certain threshold.

Second, when decomposing the global welfare loss due to imperfect competition into a 'conservation effect' (slower extraction due to a higher initial oil price) and a 'sequence effect' (front-loading of extraction of the relatively expensive and dirty resource), we find that the sequence effect, which so far has remained unexplored in the literature, is huge in our calibrated model. In the benchmark scenario, imperfect competition causes a social welfare loss of 14.5 percent of first-best welfare, almost all of which (97 percent) is imputable to the inefficient order of use of the resources, i.e. the sequence effect. Furthermore, imperfect competition increases the discounted value of climate damages by 5.3 percent compared to the first-best. Without the sequence effect, imperfect competition would decrease climate damages by 4.8 percent compared to the first-best, due to the conservation effect.

Third, in our benchmark scenario a renewables subsidy decreases OPEC's (relatively clean) initial supply, but increases the initial (relatively dirty) supply by the fringe. Hence, the average carbon content of initial resource extraction increases. Furthermore, initial aggregate emissions go up: a subsidy rate equal to 10 percent of renewables unit production costs increases initial carbon emissions by 12 percent (with equal emission factors the increase in initial emissions would have been 8.3 percent).

Fourth, the shale oil revolution characterized by an increase in shale oil reserves and 
a decrease in shale oil extraction costs, has not only increased climate damages, but may also have lowered 'grey welfare' because the relatively expensive shale oil partially crowds out early extraction of cheap oil by the cartel. We numerically investigate conditions under which the recent boom in shale oil reserves reduces global welfare.

Our numerical results are obtained within a calibrated stylized model. A caveat is therefore in order. The numbers we obtain are useful only to gain insight into the possible relative magnitudes of the different effects examined. Some remarks on the scope of our study are in order at this point as well. We only consider two types of oil reserves; this clarifies the exposition and the relevant mechanisms at the expense of more realism and more accurate estimates of the effects we measure. We consider linear extraction costs, thus in our model cumulative extraction is exogenous: climate damage effects merely result from changes in the timing of extraction of different types of oil. Therefore, our analysis mainly applies to the extraction of relatively cheap oil that is available at roughly constant marginal costs and in finite amounts (and not to more expensive oil that is available in larger amounts and at higher, reservedependent extraction costs). Still, the initial aggregate proven oil reserves that we use in our calibrated model contain 839 tonnes of $\mathrm{CO}_{2}$ (EIA, 2017a), which already is about 84 percent of the remaining carbon budget corresponding to the scenario of keeping the average global temperature rise below 2 degrees Celsius with a 50 percent probability (McGlade and Ekins, 2015). Our results show that even with fixed cumulative emissions, the change in the timing of extraction of the proven oil reserves due to imperfect competition, the shale oil revolution, and policy measures already generate substantial climate damage and welfare effects.

The importance of the inefficient order of use of the different oil reserves is corroborated by the recent findings of Asker et al. (2017). While we use a stylized model with two different types of reserves, they use a rich micro-dataset on production costs and reserves of 11,455 oil fields (constituting 99.9 percent of global reserves). They construct a counterfactual scenario for the period 1970-2100 (when all reserves are assumed depleted) in which these fields are extracted according to the Herfindahl rule, where from 2014 until 2100 it is assumed that oil demand increases at an annual rate of 1.3 percent and actual production satisfies the Herfindahl rule. Asker et al. (2017) find that the total costs of production misallocation between oil fields add up to 744 billion US\$ (measured at 2014 prices), which equals 30 percent of the present value of actual extraction costs since 1970. Furthermore, they show that 22 percent of this efficiency loss (i.e., 163 billion US\$) can be attributed to OPEC's market power. It is interesting to note that while both Asker et al. (2017) and our paper point to the importance of the inefficiencies due to OPEC's market power, we get to this conclusion from quite 
different approaches, an indication of the robustness of our results.

In contrast with Asker et al. (2017), in our paper the time path of aggregate oil supply is not exogenous. The extraction paths for the entire time horizon are obtained as equilibrium paths from a theoretical model of resource extraction that incorporates market power, competition by a fringe and the existence of a backstop technology. After fully characterizing the market equilibrium, we calibrate our model on the global oil market and examine different scenarios (e.g., first-best, perfect competition, cartelfringe). Hence, we take into account that market power not only influences the order but also the speed of extraction. Moreover, while Asker et al. (2017) limit their attention to the production cost inefficiency due to OPEC's market power, we examine the repercussions of the order of extraction for global warming, due to differences in both extraction costs as well as carbon emissions factors between oil fields. Furthermore, we use our theoretical model to examine different environmental policies' implications and to perform a welfare analysis.

The remainder of the paper is structured as follows. Section 2 outlines the model. Section 3 characterizes the cartel-fringe equilibrium and provides a comparative statics analysis. Section 4 discusses welfare effects. Finally, Section 5 concludes.

\section{The model}

A non-renewable resource is jointly supplied by a price-taking fringe and a cartel with market power. The fringe is endowed with an aggregate initial stock $S_{0}^{f}$ and has a constant per unit extraction cost $k^{f}$. The initial stock of the cartel is denoted by $S_{0}^{c}$. The per unit extraction cost of the cartel is constant and denoted by $k^{c}$. Extraction rates at time $t \geq 0$ by the fringe and the cartel are $q^{f}(t)$ and $q^{c}(t)$, respectively. The time argument will be dropped when possible. Inverse demand of the non-renewable resource is given by $p+\tau=\alpha-\beta\left(q^{f}+q^{c}\right)$, with $\alpha>0$ and $\beta>0$, where $\tau$ denotes a constant specific tax on resource consumption and $p$ is the price received by suppliers of the resource. Hence, $p+\tau$ is the consumer price. A perfect substitute for the resource can be produced, indefinitely, at marginal cost $b>0$, by using a backstop technology. We abstract from technological progress (cf. Fischer and Salant, 2014), as well as from set-up costs. Consumption of the substitute is subsidized at a constant specific rate $\sigma .^{3}$ Define $\hat{b} \equiv b-\sigma-\tau$ and denote the interest rate by $r>0$.

\footnotetext{
${ }^{3}$ The constancy of the tax can be motivated by constant marginal damages of emissions. Constancy of the renewables subsidy is convenient for the results' exposition.
} 
The fringe maximizes its discounted profits,

$$
\int_{0}^{\infty} e^{-r t}\left(p(t)-k^{f}\right) q^{f}(t) d t
$$

taking the price path as given, subject to its resource constraint

$$
\dot{S}^{f}(t)=-q^{f}(t), S^{f}(t) \geq 0 \text { for all } t \geq 0 \text {, and } S^{f}(0)=S_{0}^{f} .
$$

The cartel is aware of its influence on the equilibrium price and maximizes

$$
\int_{0}^{\infty} e^{-r t}\left(\alpha-\beta\left(q^{f}(t)+q^{c}(t)\right)-\tau-k^{c}\right) q^{c}(t) d t
$$

taking the time path of $q^{f}$ as given, subject to its resource constraint

$$
\dot{S}^{c}(t)=-q^{c}(t), S^{c}(t) \geq 0 \text { for all } t \geq 0 \text {, and } S^{c}(0)=S_{0}^{c}
$$

Moreover, the existence of the perfect substitute effectively implies an upper limit on the price the cartel can ask, yielding the additional constraint

$$
\alpha-\beta\left(q^{f}(t)+q^{c}(t)\right)-\tau \leq \hat{b}
$$

We make the following assumption.

Assumption 1 (Relative costs) We impose:

(i) $k^{c}+\tau<k^{f}+\tau<b-\sigma<\alpha$.

(ii) $k^{f}<\left(\alpha-\tau+k^{c}\right) / 2$.

Assumption 1 enables us to restrict our attention to cases that we think are empirically relevant. Part (i) ensures that the tax-inclusive marginal production costs of the non-renewable resource are lower than the after-subsidy marginal production costs of the backstop technology, and that the after-tax and after-subsidy marginal production costs are below the choke price. Part (ii) makes sure that the marginal extraction costs of the fringe are below the profit-maximizing price of the cartel. ${ }^{4}$

\footnotetext{
${ }^{4}$ To see this, consider the extreme case with an infinitely large $S_{0}^{c}$, implying a zero scarcity rent. Instantaneous marginal profits of the cartel (if $q^{f}=0$ ) are then given by $\alpha-\tau-2 \beta q^{c}-k^{c}$. Hence, the profit-maximizing price is $p^{*}=\left(\alpha-\tau+k^{c}\right) / 2$. Condition (ii) in Assumption 1 implies $k^{f}<p^{*}$.
} 


\section{Cartel-fringe equilibrium}

In this section, we first introduce the equilibrium concept. Subsequently, after describing different extraction phases we provide a full characterization of the cartel-fringe equilibrium. Finally, we perform a comparative statics analysis.

\subsection{Equilibrium concept}

The cartel chooses an extraction path, taking the extraction path of the fringe as given while the fringe takes the price path as given and chooses its extraction path.

Definition 1 A vector of functions $q \equiv\left(q^{c}, q^{f}\right)$ with $q(t) \geq 0$ for all $t \geq 0$ is a Cartel-Fringe Equilibrium (CFE) if

(i) each extraction path of the vector $\left(q^{c}, q^{f}\right)$ satisfies the corresponding resource constraint,

(ii)

$$
\begin{aligned}
& \int_{0}^{\infty} e^{-r s}\left[\alpha-\beta\left(q^{c}(s)+q^{f}(s)\right)-\tau-k^{c}\right] q^{c}(s) d s \\
& \geq \int_{0}^{\infty} e^{-r s}\left[\alpha-\beta\left(\hat{q}^{c}(s)+q^{f}(s)\right)-\tau-k^{c}\right] \hat{q}^{c}(s) d s
\end{aligned}
$$

for all $\hat{q}^{c}$ satisfying the resource constraint, and

(iii)

$$
\int_{0}^{\infty} e^{-r s}\left[p(s)-k^{c}\right] q^{f}(s) d s \geq \int_{0}^{\infty} e^{-r s}\left[p(s)-k^{c}\right] \hat{q}^{f}(s) d s
$$

where $p(s)=\alpha-\tau-\beta\left(q^{c}(s)+q^{f}(s)\right)$, for all $\hat{q}^{f}$ satisfying the resource constraint.

We use an optimal control approach to characterize a CFE. The Hamiltonian associated with the fringe's problem reads

$$
\mathcal{H}^{f}=e^{-r t}\left(p(t)-k^{f}\right) q^{f}(t)+\lambda^{f}(t)\left[-q^{f}(t)\right] .
$$

The necessary conditions include

$$
\begin{aligned}
p(t)=\alpha-\tau-\beta\left(q^{f}(t)+q^{c}(t)\right) & \leq k^{f}+\lambda^{f} e^{r t}, \\
{\left[k^{f}+\lambda^{f} e^{r t}-\alpha+\tau+\beta\left(q^{f}(t)+q^{c}(t)\right)\right] q^{f}(t) } & =0, \\
\dot{\lambda}^{f} & =0 .
\end{aligned}
$$


Here, $\lambda^{f}$ is the fringe's shadow price of the resource stock. Hence, (7a)-(7c) say that in an equilibrium with positive supply of the fringe, the producer price satisfies Hotelling's rule: the net price, $p-k^{f}$, increases over time at the rate of interest. The shadow price of the resource stock is constant over time since extraction costs do not depend on the stock.

The Lagrangian associated with the cartel's problem is given by

$$
\begin{aligned}
\mathcal{L}^{c}= & e^{-r t}\left[\alpha-\beta\left(q^{f}(t)+q^{c}(t)\right)-\tau-k^{c}\right] q^{c}(t)+\lambda^{c}\left[-q^{c}(t)\right] \\
& +\mu^{c}(t)\left[b-\sigma-\alpha+\beta\left(q^{f}(t)+q^{c}(t)\right)\right] .
\end{aligned}
$$

The necessary conditions include

$$
\begin{aligned}
\alpha-\tau-\beta\left(q^{f}(t)+2 q^{c}(t)\right) \leq k^{c}+\lambda^{c} e^{r t}-\mu^{c} \beta e^{r t}, & \\
{\left[k^{c}+\lambda^{c} e^{r t}-\mu^{c} \beta e^{r t}-\alpha+\tau+\beta\left(q^{f}(t)+2 q^{c}(t)\right)\right] q^{c}(t) } & =0, \\
\mu^{c}(t)\left[b-\sigma-\alpha+\beta\left(q^{f}(t)+q^{c}(t)\right]=0 ; \mu^{c}(t)\right. & \geq 0, \\
\dot{\lambda}^{c} & =0,
\end{aligned}
$$

where $\lambda^{c}$ denotes the shadow price of the resource stock of the cartel and $\mu^{c}$ is the Lagrange multiplier associated with restriction (5). Hence, conditions (9a)-(9d) imply that as long as $p<\hat{b}$ (i.e., as long as restriction (5) is non-binding) and $q^{c}>0$, marginal profit of the cartel increases over time at the rate of interest. Because the cartel is free to choose the moment of depletion of its stock, in equilibrium the Hamiltonian vanishes at date $T^{c}$, defined as the date at which the cartel's resource stock is depleted, implying

$$
\left(p\left(T^{c}\right)-k^{c}-\lambda^{c} e^{r T^{c}}\right) q^{c}\left(T^{c}\right)=0 .
$$

\subsection{Phases of resource extraction}

In a CFE, different phases of resource extraction may exist. By $F, C, S$ and $L$ we denote phases with only the fringe supplying, only the cartel supplying at a price strictly below $\hat{b}$, simultaneous supply, and supply by the cartel at price $\hat{b}$ (i.e., limit pricing), respectively.

We first summarize the necessary conditions that hold in each phase (Lemma 1) and then proceed by elimination of specific sequences of phases (Lemma 2). From these two lemmata we characterize a CFE in Section 3.3. 
Lemma 1 Along $F$ we have

$$
\begin{aligned}
p(t) & =\alpha-\tau-\beta q^{f}(t)=k^{f}+\lambda^{f} e^{r t}, \\
p(t) & =\alpha-\tau-\beta q^{f}(t) \leq k^{c}+\lambda^{c} e^{r t}, \\
q^{f}(t) & =\frac{1}{\beta}\left(\alpha-\tau-k^{f}-\lambda^{f} e^{r t}\right) .
\end{aligned}
$$

Along $S$ we have

$$
\begin{aligned}
p(t)= & \alpha-\tau-\beta\left(q^{f}(t)+q^{c}(t)\right)=k^{f}+\lambda^{f} e^{r t}, \\
& \alpha-\tau-\beta\left(q^{f}(t)+2 q^{c}(t)\right)=k^{c}+\lambda^{c} e^{r t}, \\
q^{f}(t)= & \left.\frac{1}{\beta}\left(\alpha-\tau-2\left(k^{f}+\lambda^{f} e^{r t}\right)+k^{c}+\lambda^{c} e^{r t}\right)\right), \\
q^{c}(t)= & \frac{1}{\beta}\left(k^{f}+\lambda^{f} e^{r t}-k^{c}-\lambda^{c} e^{r t}\right) .
\end{aligned}
$$

Along $C$ we have

$$
\begin{aligned}
p(t)= & \left.\alpha-\tau-\beta q^{c}(t)\right) \leq k^{f}+\lambda^{f} e^{r t}, \\
& \left.\alpha-\tau-2 \beta q^{c}(t)\right)=k^{c}+\lambda^{c} e^{r t}, \\
q^{c}(t)= & \frac{1}{2 \beta}\left(\alpha-\tau-k^{c}-\lambda^{c} e^{r t}\right) .
\end{aligned}
$$

Along L we have

$$
\begin{aligned}
& p(t)=\hat{b}, \\
& q^{c}(t)=q_{L} \equiv \frac{\alpha-\tau-\hat{b}}{\beta}, \\
& k^{c}+\lambda^{c} e^{r t}>\alpha-\tau-2 \beta q_{L}=2 \hat{b}-\alpha+\tau .
\end{aligned}
$$

Proof. Straightforward from the application of the Maximum Principle to the problem of the cartel and the fringe. Rewriting conditions (7a), (7b), (9a), (9b), (9c) and (10) in each phase yields the results. Expression (14c) is obtained from (9b) with $\mu^{c}>0$ imposed.

During the limit-pricing phase $L$, the producer price is constant and equal to $\hat{b}$ and therefore (11a) and (12a) cannot hold: the fringe's production is nil. Condition (14c) is illustrated in Figure 1, which exhibits marginal revenue (discontinuous solid line) and marginal costs (dashed line). Marginal revenue jumps at $q=q_{L}$, and when $\hat{b} \geq$ $k^{c}+\lambda^{c} e^{r t} \geq 2 \hat{b}-\alpha+\tau$ marginal revenue is not smaller (not larger) than marginal cost 
for $q<(>) q_{L}$, implying that the profit maximizing quantity is $q_{L}$. When $\hat{b}=k^{c}+\lambda^{c} e^{r t}$, marginal revenue equals full marginal cost for any $q \in\left[0, q_{L}\right]$. However, the equilibrium outcome yields $q_{L}$ because of discounting.

Figure 1: Discontinuous marginal revenue and limit pricing

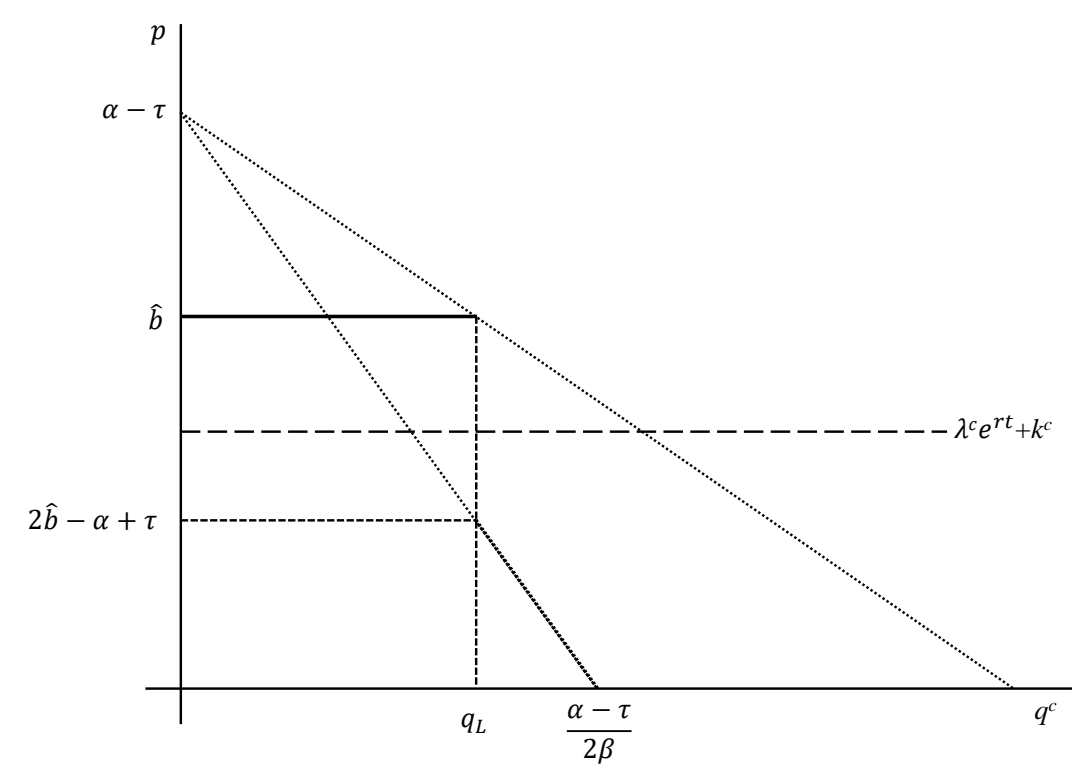

We denote the cartel's marginal profit during limit pricing by ${ }^{5}$

$$
\hat{\pi} \equiv 2 \hat{b}-\alpha+\tau-k^{c}
$$

If $\hat{\pi} \leq 0$, condition (14c) always holds. Therefore, as soon as the stock of the fringe is exhausted the equilibrium exhibits limit pricing. Intuitively, if marginal profits remain non-positive for all $p \leq \hat{b}$, once the fringe's stock is depleted the cartel will set the highest possible price (of course, given that they still have a positive remaining stock). If $\hat{\pi}>0$, we get from (9b) and (10) that the duration of the limit-pricing phase can be at most

$$
\hat{\Delta} \equiv \frac{1}{r} \ln \left(\frac{\hat{b}-k^{c}}{\hat{\pi}}\right),
$$

where the term between brackets equals average profits over marginal profits during limit pricing. We denote a limit-pricing phase of duration $\hat{\Delta}$ by $\hat{L}$. The phase $\hat{L}$ also

\footnotetext{
${ }^{5}$ Define marginal profits of the cartel as $\pi\left(q^{c}, q^{f}\right) \equiv \alpha-\beta\left(q^{c}+q^{f}\right)-k^{c}-\tau-\beta q^{c}$. Evaluate at $q^{f}=0$ and $q^{c}=q_{L}=\frac{\alpha-\tau-\hat{b}}{\beta}$ to get $\hat{\pi}=\pi\left(q_{L}, 0\right)=2 \hat{b}-\alpha+\tau-k^{c}$.
} 
requires a minimum amount of stock: $\hat{S}_{L} \equiv q_{L} \hat{\Delta}$. A limit-pricing phase with a duration different from $\hat{\Delta}$ is denoted by $\tilde{L}$.

We proceed by investigating which sequences of phases are possible in equilibrium. Lemma 2 lists all sequences of phases that can be ruled out because they violate the necessary conditions.

\section{Lemma 2 In a CFE}

(i) A direct transition from $C$ to $F$ or vice versa is excluded.

(ii) The initial regime is not $C$.

(iii) $F$ before $S$ is excluded.

(iv) $F \rightarrow \hat{L}$ and $F \rightarrow \tilde{L}$ are excluded.

Proof. See Appendix A.1.

Intuitively, (i) must hold in equilibrium because a direct transition from $C$ to $F$ or vice versa with a continuous price would imply a jump in $q^{f}$ and therefore a jump in marginal profits of the cartel at the moment of the transition. Furthermore, (ii) must hold in equilibrium because if only the cartel is extracting, Assumption 1 ensures that the oil price exceeds the unit extraction costs of the fringe and that the net price of the fringe, $p-k^{f}$, is growing at a rate lower than the rate of interest. Therefore, the fringe prefers current extraction over future extraction and will undercut the cartel, implying that a $C$-phase cannot occur before depletion of the fringe's stock. Similarly, (iii) and (iv) must hold. Indeed suppose there is a phase where the fringe is the sole supplier before the cartel's stock is depleted. During that phase the fringe's net price growth rate equals the interest rate. Because the unit extraction costs of the cartel are smaller than the fringe's unit extraction cost, this would imply that the cartel's net price, $p-k^{c}$ (which equals its marginal profit if $q^{c}=0$ ), grows at a rate lower than the rate of interest. Hence, the cartel prefers current extraction over future extraction and will undercut the fringe.

\subsection{Characterization of a CFE}

The strategy to characterize a CFE is to consider for a given stock $S_{0}^{f}$ which phases occur in equilibrium depending on the stock $S_{0}^{c}$. To this end it will be helpful to define two threshold stocks $S_{0 S}^{c}$ and $\hat{S}_{0}^{c}$. We first identify the conditions to obtain a CFE that consists of only $S$. 
Lemma 3 Let $S_{0}^{f}$ be given. Suppose a CFE consists of only $S$, with final time $T_{S}$. Then $T_{S}$ and the required $S_{0}^{c}$ satisfy

$$
\begin{aligned}
r \beta S_{0}^{f} & =\left(\hat{b}+k^{c}-2 k^{f}\right)\left(r T_{S}-1+e^{-r T_{S}}\right)+(\alpha-\tau-\hat{b}) r T_{S} \\
r \beta S_{0}^{c} & =\left(k^{f}-k^{c}\right)\left(r T_{S}-1+e^{-r T_{S}}\right) .
\end{aligned}
$$

Proof. See Appendix A.2.

This system defines a one to one relationship between $S_{0}^{f}$ and $S_{0}^{c}$ that yields an equilibrium $S$. Given $S_{0}^{f}$ the system defines a unique $S_{0 S}^{c}=\Phi\left(S_{0}^{f}\right)$ such that the equilibrium is $S$ when the initial stocks are $\left(S_{0}^{f}, S_{0 S}^{c}\right)$. It can be shown that the function $\Phi$ is strictly increasing. So for each $S_{0}^{c}$ we have an equilibrium that reads $S$ when $S_{0 S}^{f}=\Phi^{-1}\left(S_{0}^{c}\right)$. Hence, we have established the following result.

Lemma 4 For each $S_{0}^{f}$ there exists a unique $S_{0 S}^{c}$ such that the equilibrium reads $S .{ }^{6}$

\subsubsection{When the fringe depletes last}

We investigate the equilibrium outcome when, for a given $S_{0}^{f}$, we have $S_{0}^{c}<S_{0 S}^{c}$. We establish that the sequence of regimes reads $S \rightarrow F$.

Lemma 5 Given $S_{0}^{f}$, the equilibrium reads $S \rightarrow F$ when $S_{0}^{c}<S_{0 S}^{c}$. When $S_{0}^{c}$ approaches $S_{0 S}^{c}$ from below, the duration of the F-phase tends to zero.

Proof. See Appendix A.3.

\subsubsection{When the fringe depletes first}

Here we examine the possible outcomes when, given $S_{0}^{f}$, we have $S_{0}^{c}>S_{0 S}^{c}$. We establish that there will then be a final limit-pricing phase. We start by considering the special case of the equilibrium $S \rightarrow \hat{L}$.

Lemma 6 Let $S_{0}^{f}$ be given. Suppose the equilibrium sequence reads $S \rightarrow \hat{L}$ with transition at $\hat{T}_{S}$ and final time $\hat{T}_{L}$. Then $\hat{T}_{S}, \hat{T}_{L}$, and the required $S_{0}^{c}$ satisfy

$$
\begin{aligned}
r \beta S_{0}^{f}= & \left(\alpha-\tau+k^{c}-2 k^{f}\right)\left(r \hat{T}_{S}-1+e^{-r \hat{T}_{S}}\right), \\
r \beta S_{0}^{c}= & \left.\left(\hat{b}-\alpha+\tau+k^{f}-k^{c}\right)\right)\left(r \hat{T}_{S}-1+e^{-r \hat{T}_{S}}\right) \\
& +(\alpha-\tau-\hat{b}) r \hat{T}_{L}, \\
\left(\hat{b}-k^{c}\right) e^{-r \hat{T}_{L}}= & {\left[2 \hat{b}-\alpha+\tau-k^{c}\right] e^{-r \hat{T}_{S}} . }
\end{aligned}
$$

${ }^{6}$ Note that $S_{0 S}^{c}$ is a function of $S_{0}^{f}$. However, for the ease of exposition we omit the argument and only use the notation $S_{0 S}^{c}$ throughout the rest of the paper. 
Proof. See Appendix A.4.

We show in the next lemma that for any given initial stock of the fringe, the existence of this equilibrium requires a unique initial stock of the cartel. Moreover, the length of the $S$-phase is larger than in the equilibrium where there is only an $S$-phase (Lemma 4). We will distinguish cases with positive (Lemma 7-9) and negative (Lemma 10) marginal profits of the cartel during limit-pricing.

Lemma 7 Suppose marginal profits during limit pricing are positive, i.e., $\hat{\pi}>0$. Then:

(i) For each $S_{0}^{f}$, there exists a unique $\hat{S}_{0}^{c}$ such that the equilibrium reads $S \rightarrow \hat{L}$.

(ii) $\hat{T}_{S}>T_{S}$ and $\hat{S}_{0}^{c}>S_{0 S}^{c}+\hat{S}_{L}$.

Proof. See Appendix A.5.

Note that the duration of the limit-pricing phase depends on the marginal profit of the cartel at the end of the $S$-phase. This can be seen by combining (9b) and (10), yielding

$$
\tilde{\Delta}=\frac{1}{r} \ln \left(\frac{\hat{b}-k^{c}}{\hat{b}-\beta q^{c}\left(T^{-}\right)-k^{c}}\right),
$$

where $\tilde{\Delta}$ denotes the duration of limit pricing and $T^{-} \equiv \lim _{t \uparrow T} t$ denotes the end of the $S$-phase. It follows from Lemma 7 that if $S_{0}^{c}$ equals the threshold $\hat{S}_{0}^{c}$, we have $\tilde{\Delta}=\hat{\Delta}$. Equating (16) and (19) then makes clear that the cartel serves the entire market at the end of the $S$-phase, i.e., $q^{c}\left(T^{-}\right)=q_{L}$ and $q^{f}\left(T^{-}\right)=0$.

The next lemma provides the equilibrium when the initial stock of the cartel exceeds the threshold $\hat{S}_{0}^{c}$.

Lemma 8 Suppose marginal profits during limit pricing are positive, i.e., $\hat{\pi}>0$. Given $S_{0}^{f}$ then for any $S_{0}^{c}>\hat{S}_{0}^{c}$ the equilibrium reads $S \rightarrow C \rightarrow \hat{L}$.

Proof. See Appendix A.6.

Intuitively, compared to the equilibrium in Lemma 7, the duration of the limit-pricing phase cannot increase, as is clear from (19), because the cartel is already serving the entire market at the end of the $S$-phase. As a result, the increase in the initial stock of the cartel gives rise to the occurrence of an intermediate $C$-phase before limit-pricing starts.

Lemma 9 characterizes the equilibrium when, given $S_{0}^{f}$, the initial stock of the cartel falls short of the threshold $\hat{S}_{0}^{c}$, but still exceeds $S_{0 S}^{c}$. 
Lemma 9 Suppose marginal profits during limit pricing are positive, i.e., $\hat{\pi}>0$. Given $S_{0}^{f}$ then for any $S_{0}^{c} \in\left(S_{0 S}^{c}, \hat{S}_{0}^{c}\right)$ the equilibrium reads $S \rightarrow \tilde{L}$.

Proof. See Appendix A.7.

In this case, the cartel still has a positive remaining stock at the end of the $S$-phase, but the remaining stock size is insufficient to have a final limit-pricing phase $\hat{L}$ of duration $\hat{\Delta}$. As a result, there will be limit pricing for a shorter period of time. Therefore, the market share of the cartel at the end of the $S$-phase, $q^{c} / q_{L}$, in this equilibrium will be smaller than in the equilibria described in the previous two lemmata. Moreover, this market share will converge to zero if $S_{0}^{c}$ converges to $S_{0 S}^{c}$ (and therefore $\tilde{\Delta}$ converges to zero), as can be noticed from (19).

We now consider the case where $\hat{\pi} \leq 0$.

Lemma 10 Suppose marginal profits during limit pricing are non-positive, i.e., $\hat{\pi} \leq 0$. Then for any $S_{0}^{c} \geq S_{0 S}^{c}$ the equilibrium reads $S \rightarrow \tilde{L}$.

Proof. See Appendix A.8.

Intuitively, if the cartel has an initial stock large enough to end up with a positive remaining stock at the moment when the fringe's stock is depleted, non-positive marginal profits imply that it will maximize profits by adopting a limit-pricing strategy from that moment onwards until depletion, irrespective of the size of its remaining resource stock.

\subsubsection{Full characterization}

We are now ready to give a full characterization of the CFE. The results from Lemma 1-10 are collected into Proposition 1.

\section{Proposition 1 (Characterization of the equilibrium)}

(i) Suppose marginal profits during limit pricing are non-positive, i.e., $\hat{\pi} \leq 0$. Then for any given $S_{0}^{f} \geq 0$, there exists a unique $S_{0 S}^{c}$ such that:

(a) If $S_{0}^{c}<S_{0 S}^{c}$ the equilibrium reads $S \rightarrow F$,

(b) If $S_{0}^{c}=S_{0 S}^{c}$ the equilibrium reads $S$,

(c) If $S_{0}^{c}>S_{0 S}^{c}$ the equilibrium reads $S \rightarrow \tilde{L}$.

(ii) Suppose marginal profits during limit pricing are positive, i.e., $\hat{\pi}>0$. Then for any given $S_{0}^{f} \geq 0$, there exists a unique $S_{0 S}^{c}$ and a unique $\hat{S}_{0}^{c}>S_{0 S}^{c}$, such that: 
(a) If $S_{0}^{c}<S_{0 S}^{c}$ the equilibrium reads $S \rightarrow F$,

(b) If $S_{0}^{c}=S_{0 S}^{c}$ the equilibrium reads $S$,

(c) If $S_{0}^{c} \in\left(S_{0 S}^{c}, \hat{S}_{0}^{c}\right)$ the equilibrium reads $S \rightarrow \tilde{L}$,

(d) If $S_{0}^{c}=\hat{S}_{0}^{c}$ the equilibrium reads $S \rightarrow \hat{L}$,

(e) If $S_{0}^{c}>\hat{S}_{0}^{c}$ then the equilibrium reads $S \rightarrow C \rightarrow \hat{L}$.

Figure 2: Characterization of the equilibrium

Panel (a) - Non-positive marginal profits at limit price
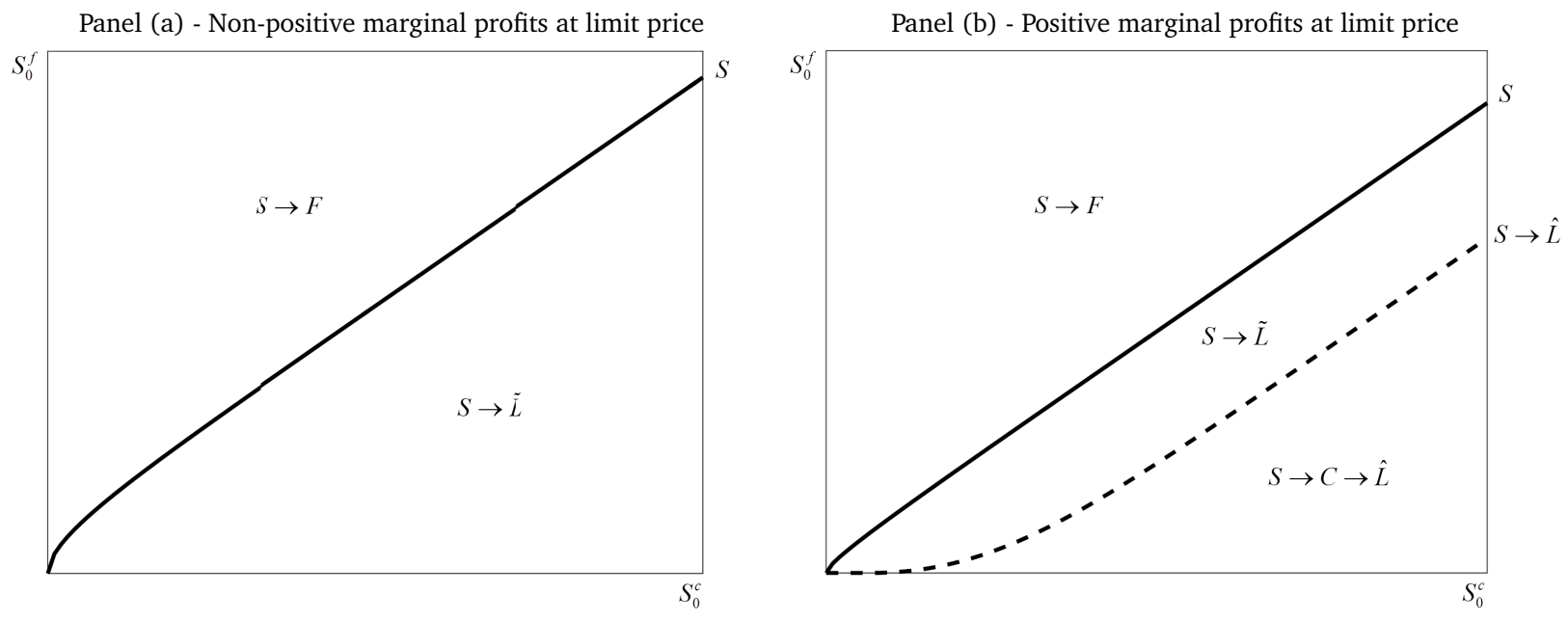

Figure 2 illustrates the equilibrium sequence for different combinations of the initial resource stock of the cartel (horizontal axis) and the fringe (vertical axis). Panel (a) shows the case with non-positive marginal profits during limit pricing (part (i) of the proposition), whereas panel (b) shows the case with positive marginal profits during limit pricing (part (ii) of the proposition).

\subsection{Comparative statics}

We apply our analysis in the context of climate change and examine the effect of specific climate change policies on the equilibrium outcomes. In a cartel-fringe equilibrium, the effects of climate change policies differ markedly from those under the extreme circumstances of perfect competition and monopoly. We investigate these effects.

Proposition 2 discusses the effect of a renewables subsidy on initial oil extraction.

\section{Proposition 2 (Renewables subsidy and initial extraction)}

(i) If the equilibrium reads $S \rightarrow F$, a marginal increase in the renewables subsidy increases initial extraction by the fringe and does not affect initial extraction by the cartel. 
(ii) If the equilibrium reads $S \rightarrow C \rightarrow \hat{L}$, a marginal increase in the renewables subsidy decreases initial extraction by the cartel and does not affect initial extraction by the fringe.

Proof. See Appendix A.9.

To understand the results in Proposition 2, it is helpful to consider the extreme cases of perfect competition and pure monopoly. Under perfect competition, a subsidy for renewables increases initial extraction. This is the standard Green Paradox effect discussed by Sinn $(2008,2012)$. The reason is that by making renewables cheaper, the subsidy lowers the future market price of oil. As a result, resource owners respond by depleting their stock more rapidly, which increases initial extraction. With monopolistic resource supply, on the contrary, the resource owner responds to a renewables subsidy by increasing the initial price and thereby lowering extraction (as long as she does not adopt limit pricing from the beginning). In so doing, the monopolist effectively postpones entry of renewables producers (cf. Gilbert and Goldman, 1978; Hoel, 1983; Van der Meijden and Withagen, 2016).

As long as the initial aggregate stock of the cartel is small relative to that of the fringe, the equilibrium reads $S \rightarrow F$ (Proposition 1, parts (ia) and (iia)). In this case, the perfectly competitive mechanism dominates, implying that initial supply goes up in response to an increase in the renewables subsidy (part (i) of Proposition 2). However, if the initial aggregate stock of the cartel is relatively large and if marginal profits during limit pricing are positive, the equilibrium sequence reads $S \rightarrow C \rightarrow \hat{L}$ (Proposition 1 , part (iie)). In that case, the monopolistic mechanism dominates and initial extraction decreases upon a rise in the renewables subsidy (part (ii) of Proposition 2).

In the intermediate $S \rightarrow \tilde{L}$ equilibrium (Proposition 1, parts (ic) and (iic)) the effect of a renewables subsidy on initial extraction is ambiguous. In Section 4.4, we numerically analyze this case, as the equilibrium in our calibrated model reads $S \rightarrow \tilde{L}$.

Proposition 3 considers the effects of climate policy on the duration of limit pricing and the time of depletion.

\section{Proposition 3 (Policy and extraction duration)}

(i) If the equilibrium reads $S \rightarrow C \rightarrow \hat{L}$, a marginal increase in the renewables subsidy and/or the carbon tax decreases the duration of the $\hat{L}$-phase.

(ii) If the equilibrium reads $S \rightarrow F$ or $S \rightarrow C \rightarrow \hat{L}$, a marginal increase in the renewables subsidy (carbon tax) decreases (postpones) the time of depletion. 
Proof. See Appendix A.10.

The result in part (i) can be understood by noting from (16) that the duration of the limit-pricing phase depends on the proportional difference between average profits and marginal profits at the after-tax-and-subsidy renewables price $\hat{b}$. Both a renewables subsidy and a carbon tax lower this proportional difference and thus shorten the duration of the limit-pricing phase.

Part (ii) says that irrespective of the relative initial stock of the cartel and the fringe, an increase in the renewables subsidy brings forward the time of depletion, whereas a carbon tax postpones it. In the perfectly competitive case, the renewables subsidy shifts down (up) the entire resource price (extraction) path, which implies that depletion occurs sooner. Under pure monopoly, although initial extraction goes down, supply during the limit pricing phase goes up. On balance, the depletion time goes down. To understand the increase in the time of depletion upon an increase of the carbon tax, note that the carbon tax effectively increases marginal extraction costs, implying more conservative extraction.

\section{Welfare implications of the CFE}

We now exploit our analysis above to examine the quantitative importance of imperfect competition and the order of extraction of different oil reserves and the repercussions for global warming and welfare. In our framework, the fact that the fringe may start extracting before the low cost resource is exhausted is a source of inefficiency. This inefficiency is further amplified when we consider the emissions of pollution generated by oil and their impact on global warming. In this section we calibrate our model to examine the relative importance, in terms of global welfare, of the inefficient order of use of oil reserves. Our calibrated model also allows us to examine the net effect of the shale oil revolution on global welfare.

We define 'grey' welfare, $W^{G}$, as the discounted sum of consumer surplus, producer surplus and tax revenue, minus subsidy costs:

$$
\begin{aligned}
W^{G} \equiv & \int_{0}^{\bar{T}} e^{-r t}\left[\alpha\left(q^{c}+q^{f}\right)-\frac{1}{2} \beta\left(q^{c}+q^{f}\right)^{2}-k^{c} q^{c}-k^{f} q^{f}\right] d t \\
& +\frac{e^{-r \bar{T}}}{r}\left[\frac{\alpha-b}{\beta}(\alpha-\tau-\hat{b})-\frac{1}{2 \beta}(\alpha-\tau-\hat{b})^{2}\right]
\end{aligned}
$$

where $\bar{T}$ denotes the moment at which the last resource stock is depleted. ${ }^{7}$

\footnotetext{
${ }^{7}$ Alternatively, we could define a the quasi-linear utility function $U\left(q^{c}+q^{f}+x\right)=\alpha\left(q^{c}+q^{f}+x\right)-$
} 
The atmospheric stock of carbon, $E$, evolves according to

$$
\dot{E}(t)=\omega^{c} q^{c}(t)+\omega^{f} q^{f}(t)
$$

where $\omega^{c}$ and $\omega^{f}$ denote the emission factor of the cartel and the fringe, respectively. We follow Hoel (2011) and Van der Ploeg (2016) by assuming that climate damages are linear in the stock of atmospheric carbon. The discounted value of climate damage is given by:

$$
D(t)=\int_{t}^{\infty} e^{-r(s-t)} \psi E(s) d s,
$$

where $\psi>0$ denotes the instantaneous and constant marginal damage of carbon. Hence, the social cost of carbon (SCC), i.e., the discounted value of current and future marginal damages, is equal to

$$
S C C(t)=\int_{t}^{\infty} e^{-r(s-t)} \psi d s=\frac{\psi}{r} .
$$

Social welfare, $W$, is defined as the difference between grey welfare and climate damage: $W \equiv W^{G}-D$.

In determining supply, both the cartel and the fringe ignore the damage caused by their activity. Thus in our framework we have two sources of market failure: imperfect competition and a negative climate externality. The evaluation of the impact of market failure cannot entirely be captured by the level of the industry's output alone; it should also take into account the composition of aggregate extraction. Indeed, for a given path of aggregate extraction, the equilibrium involves an $S$-phase during which extraction of the high cost source occurs before the low cost reserve is exhausted. We seek to determine the relative importance of the failure due to the inefficient order of use of resources. For this purpose we compare the CFE exhibited above, with the outcomes of three scenarios: the socially optimal extraction of reserves also referred to as the first-best (FB), the perfectly competitive (PC) scenario where the cartel-the owner of the low cost reserves-is assumed to be price taker, and the 'Herfindahl scenario'. In this latter scenario, total extraction at each instant of time is the same as in the CFE, but we impose the order of resource use of the first-best; first extraction by the cartel until its stock is depleted and then extraction by the fringe until depletion. This allows us to decompose the deviation of the CFE from the first-best into a 'conservation effect' (i.e., the deviation of the Herfindahl scenario from the first-best) and a 'sequence effect'

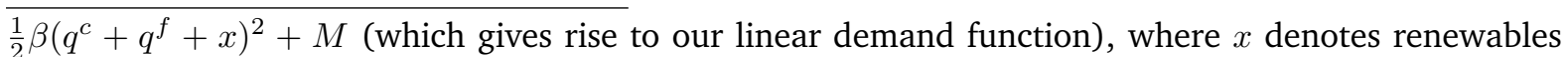
consumption and $M$ expenditure on a numeraire good. This results in the same expression for $W^{G}$. 
(i.e., the deviation of the CFE from the Herfindahl scenario).

\subsection{Calibration}

We calibrate our model by using data on proven oil reserves, global oil consumption, extraction costs, the oil price, the price elasticity of oil demand, and carbon emission factors for different types of oil. Proven reserves owned by OPEC are 1212 billion barrels (EIA, 2017a). In the rest of the world, proven reserves excluding shale oil equal 438 billion barrels (EIA, 2017a). Furthermore, according to the EIA (2013) shale oil reserves amount to 10 percent of total proven reserves, which implies another 181.5 barrels of oil for the rest of the world. For the parameters of the demand function, we use $\alpha=225.5 \mathrm{US} \$ / \mathrm{bbl}$ and $\beta=4.3 \mathrm{US} \$ / \mathrm{bbl}$ to get an initial oil demand of 34 billion barrels and an initial price of 80 dollars per barrel (roughly equal to the average crude oil consumption and crude oil price over the last decade (EIA, 2017a)) and an initial price elasticity of demand of 0.55 , which is within the range of long-run price elasticities reported by Hamilton (2009). ${ }^{8}$

Table 1: Benchmark calibration

\begin{tabular}{|c|c|c|c|}
\hline parameters & description & value & unit \\
\hline$\alpha$ & choke price & 225.5 & $\mathrm{US} \$ / \mathrm{bbl}$ \\
\hline$\beta$ & slope inverse demand function & 4.3 & $\mathrm{US} \$ / \mathrm{bbl}$ \\
\hline$b$ & renewables price & 102.5 & $\mathrm{US} \$ / \mathrm{BOE}$ \\
\hline$k^{c}$ & marginal extraction cost cartel & 18 & $\mathrm{US} \$ / \mathrm{bbl}$ \\
\hline$k^{f}$ & marginal extraction cost fringe & 62.5 & $\mathrm{US} \$ / \mathrm{bbl}$ \\
\hline$r$ & interest rate & 0.028 & perunage \\
\hline$S_{0}^{c}$ & initial stock cartel & 1212 & billion bbl \\
\hline$S_{0}^{f}$ & initial stock fringe & 619.5 & billion bbl \\
\hline$\omega^{c}$ & emission factor cartel & 0.11083 & $\mathrm{tC} / \mathrm{bbl}$ \\
\hline$\omega^{f}$ & emission factor fringe & 0.1525 & $\mathrm{tC} / \mathrm{bbl}$ \\
\hline$S C C=\psi / r$ & social costs of carbon & 250 & $\mathrm{US} \$ / \mathrm{tC}$ \\
\hline implied values & description & value & unit \\
\hline$q^{c}(0)+q^{f}(0)$ & initial oil consumption & 34 & billion bbl \\
\hline$p(0)$ & initial oil price & 80 & $\mathrm{US} \$ / \mathrm{bbl}$ \\
\hline$\left.\varepsilon q^{c}(0)+q^{f}(0)\right)$ & initial price elasticity of demand & 0.55 & elasticity \\
\hline
\end{tabular}

For the marginal extraction costs of OPEC, we use the Middle East and North African oil (MENA) estimate of 18 US\$ per barrel reported in Fischer and Salant (2017). For

\footnotetext{
${ }^{8}$ By using the price elasticity of demand $\varepsilon \equiv-\frac{d q / q}{d p /(p+\tau)}=\frac{\alpha-\beta q}{\beta q}$ together with the demand function, by imposing $\tau=0$ we obtain $\alpha=\frac{\varepsilon+1}{\varepsilon} p$ and $\beta=\frac{p}{\varepsilon q}$, yielding values for $\alpha$ and $\beta$ in terms of the observed initial $p, q$, and $\varepsilon$.
} 
the unit extraction costs of the fringe, we use a weighted average (with the oil reserves as weights) ${ }^{9}$ of the other types of oil in Fischer and Salant (2017), which gives 62.5 US\$ per barrel. ${ }^{10}$ Similarly, for the relative emission factor of the fringe (compared to OPEC) we use a weighted average of the relative emission factors of the different types of oil (excluding the MENA oil) in Fischer and Salant (2017), yielding $\omega^{f} / \omega^{c}=1.376$. For the carbon content of crude oil, we use $\omega^{c}=0.11083$ ton carbon per barrel (EPA, 2015).

For the renewables unit cost parameter we use $b=102.5$ US\$/BOE ('barrels of oil equivalent') to indeed get an initial oil use equal to 34 billion barrels in equilibrium. Our renewables unit cost corresponds to the unit costs of biofuels after 30 years in Fischer and Salant (2017). ${ }^{11}$ For the social cost of carbon, we take 250 US\$/tC (or $68 \mathrm{US} \$ / \mathrm{tCO}_{2}$ ), which is within the Nordhaus-Stern range of about 31 to $85 \mathrm{US} \$ / \mathrm{tCO}_{2}$ (Stern, 2007; Nordhaus, 2017). ${ }^{12}$ For the interest rate, we take the average of the US long-term composite rate on government bonds in 2017, which equals 2.8 percent (U.S. Department of the Treasury, 2017). ${ }^{13}$

An overview of our benchmark calibration and the implied equilibrium values is provided in Table $1 .{ }^{14}$ Because we have expressed prices and costs in US\$, welfare and climate damages are expressed in US\$ as well. The equilibrium of the calibrated model is characterized by $\hat{\pi}<0$ and the sequence $S \rightarrow \tilde{L}$.

\subsection{The effects of imperfect competition}

In this section, we discuss the effects of imperfect competition by comparing the CFE with the outcome under perfect competition, the first-best, and the Herfindahl scenario (i.e., the CFE without the sequence effect). The perfectly competitive equilibrium and the first-best are characterized in Appendix B.

Figure 3 shows the time profiles of the oil price (panel (a)) and cumulative carbon emissions (panel (b)) for the benchmark calibration. The black solid and dashed curves represent the CFE and the perfectly competitive equilibrium, respectively. The solid grey line corresponds to the first-best and the dotted line represents the Herfindahl

\footnotetext{
${ }^{9}$ Fischer and Salant (2017) use estimates for the ultimately recoverable resources reported by the IEA (2013), instead of the proven oil reserves.

${ }^{10}$ Fischer and Salant (2017) include conventional oil, enhanced oil recovery (EOR) and deep-water drilling, heavy oil, oil sands, and oil shale in their analysis.

${ }^{11}$ In their benchmark scenario, Fischer and Salant (2017) assume that the backstop cost initially equals 115 US\$/BOE and gradually falls over time, due to technological change.

${ }^{12}$ We have $S C C=\frac{\psi}{r}$. Hence, in the benchmark scenario we set $\psi=250 \cdot 0.028=7 \mathrm{US} \$ / \mathrm{tC}$.

${ }^{13}$ The long-term composite rate is the "unweighted average of bid yields on all outstanding fixedcoupon bonds neither due nor callable in less than 10 years" (U.S. Department of the Treasury, 2017).

${ }^{14} \mathrm{We}$ use tC to denote 'metric tonnes of carbon', GtC for 'gigatonnes of carbon', bbl for 'barrels of oil' (one barrel contains about 159 litres) and BOE for 'barrels of oil equivalent'.
} 
Panel (a) - Oil price (US\$/bbl)

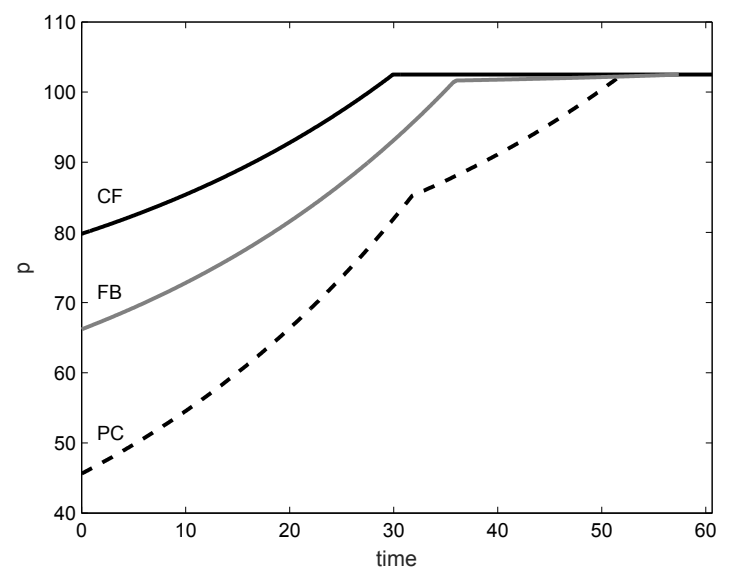

Panel (b) - Cumulative emissions (GtC)

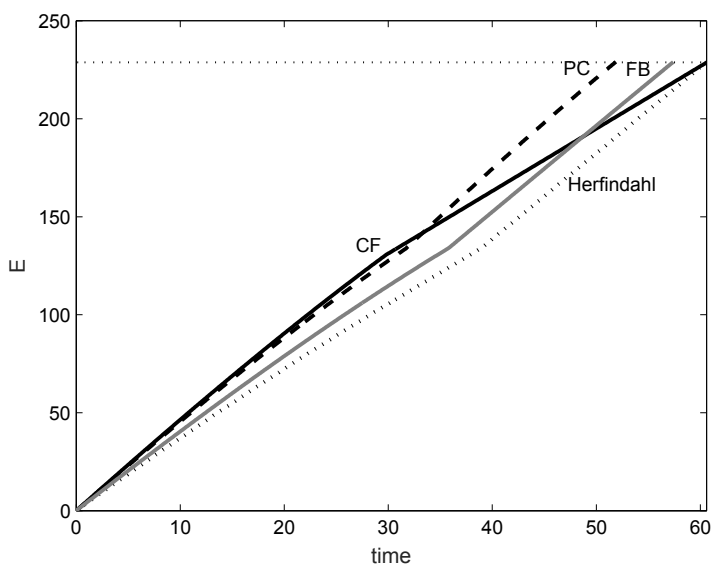

Notes: The figure shows the time profiles of the oil price (panel (a)) and cumulative carbon emissions (panel (b)). The solid (dashed) black curves correspond to the cartel-fringe, CF (perfectly competitive, PC) equilibrium. The grey curves indicate the first-best outcome, FB. The dotted line in panel (b) represents the Herfindahl scenario. Parameters are set at their benchmark values, as shown in Table 1.

scenario. As marginal profits during limit pricing are negative and the initial stock of the cartel exceeds $S_{0 S}^{c}$ in our calibration, the CFE sequence is $S \rightarrow \tilde{L}$ (see Proposition 1 $(\mathrm{i}, \mathrm{c})$ ): the cartel follows a limit-pricing strategy as soon as the fringe's stock is depleted. In the perfectly competitive equilibrium and in the first-best, the equilibrium sequence reads $C \rightarrow F$, implying that the Herfindahl rule is satisfied. The curves in panel (a) show that the time profile of the resource price in the CFE is entirely located above the perfectly competitive one, and even above the one corresponding to the first-best. Still, panel (b) shows that initially cumulative carbon emissions grow more rapidly in the CFE than under perfect competition and the first-best. The reason is that although extraction is initially lower in the CFE due to the higher oil price (conservation effect), extraction of relatively dirty oil by the fringe is front-loaded in time in the CFE (sequence effect). The dotted line shows that if we would eliminate the sequence effect, the CFE would generate a cumulative carbon emissions time profile below the one generated by each of the other cases.

Figure 4 depicts how climate damage depends on the emission factor of the fringe compared to that of the cartel. The figure shows the deviation of climate damage from the first-best, in percentage terms. When the relative emission factor equals unity, the CFE coincides with the Herfindahl scenario, as the sequence effect becomes immaterial to climate change. Due to the conservation effect, climate damage is lower than under perfect competition, and even lower than in the first-best. However, by increasing the 
Figure 4: Relative emission factors and climate damage

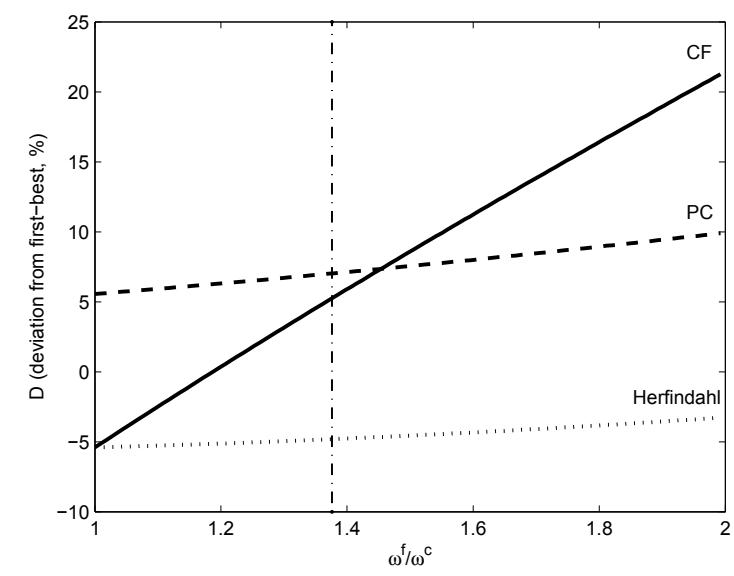

Notes: The figure shows climate damage (expressed in US\$) for various values of $\omega^{f} / \omega^{c}$. The solid (dashed) black curve corresponds to the cartel-fringe, CF (perfectly competitive, PC) equilibrium. The dotted curve represents the Herfindahl scenario. Parameters are set at their benchmark values, as shown in Table 1. The vertical line indicates the benchmark relative emission factor.

relative emission factor above 1.2, climate damage becomes higher than in the firstbest, and eventually (above 1.45) higher than under perfect competition.

Figure 5 compares the levels of grey welfare (panel (a)), climate damage (panel (b)), and social welfare (panel (c)) between the different scenarios for various values of the interest rate, which is a crucial determinant of the welfare consequences of changes in the sequence of extraction. ${ }^{15}$ Comparison of the CFE (solid line) and the Herfindahl scenario (dotted line) in the three panels learns that the difference in welfare and climate damage is mainly driven by the sequence effect. In our benchmark scenario with $r=0.028$, the grey welfare loss in the CFE, compared to the first-best (as depicted in panel (a)), is 10.3 percent, of which only 1.3 percentage points remain in the Herfindahl scenario: 87.4 percent of the grey welfare loss is driven by the sequence effect. Furthermore, at $r=0.028$ climate damage (panel (b)) is 5.3 percent higher in the CFE equilibrium than in the first-best, while the Herfindahl scenario would give a 4.8 percent lower climate damage than in the first-best. Panel (c) shows that social welfare at $r=0.028$ is 14.5 percent lower in the CFE than in the first-best, of which only 0.4 percentage points remain in the Herfindahl scenario: 97 percent of the loss in social welfare is due to the sequence effect. Panel (c) also shows that the difference between the CFE and the Herfindahl line is increasing in the rate of interest. Intuitively, the higher the rate of interest, the more important timing becomes, and the larger will be the loss in welfare due to the violation of the Herfindahl rule in the CFE.

\footnotetext{
${ }^{15}$ We offset changes in the interest rate by changes in $\psi$ in order to leave the $S C C=\psi / r$ unaffected.
} 
Figure 5: Welfare deviations from first-best

Panel (a) - Grey welfare

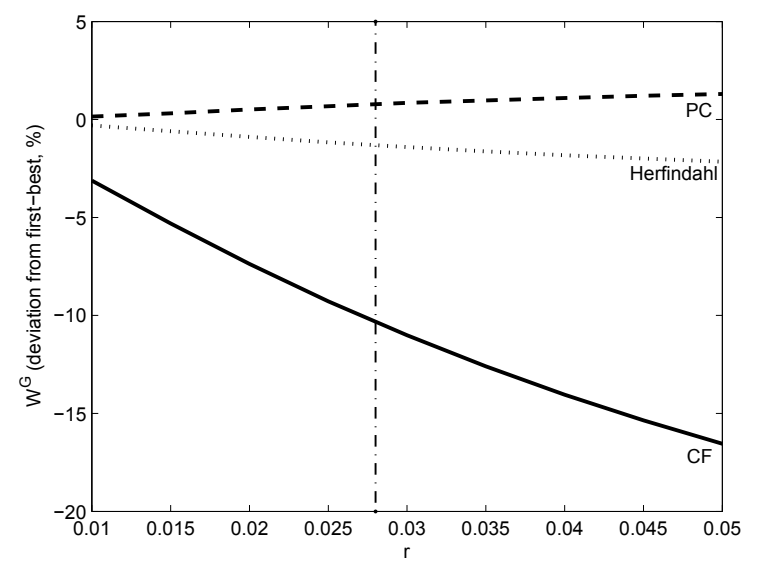

Panel (b) - Climate damage

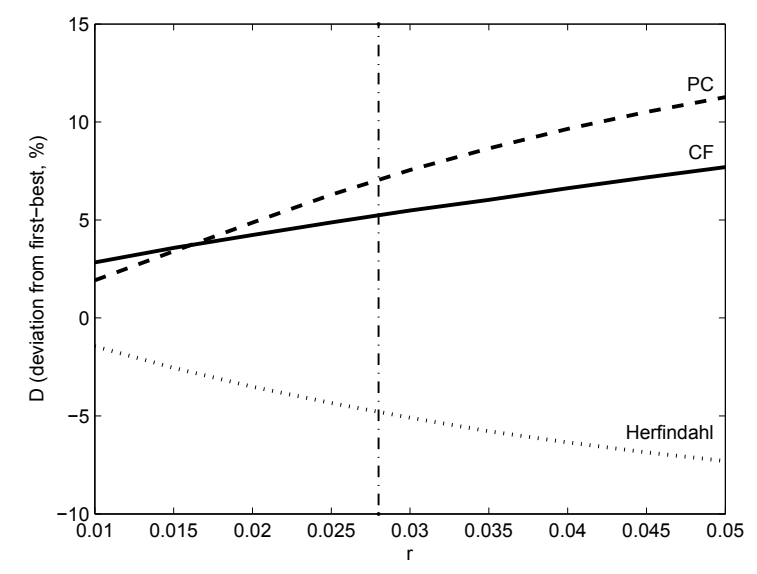

Panel (c) - Social welfare

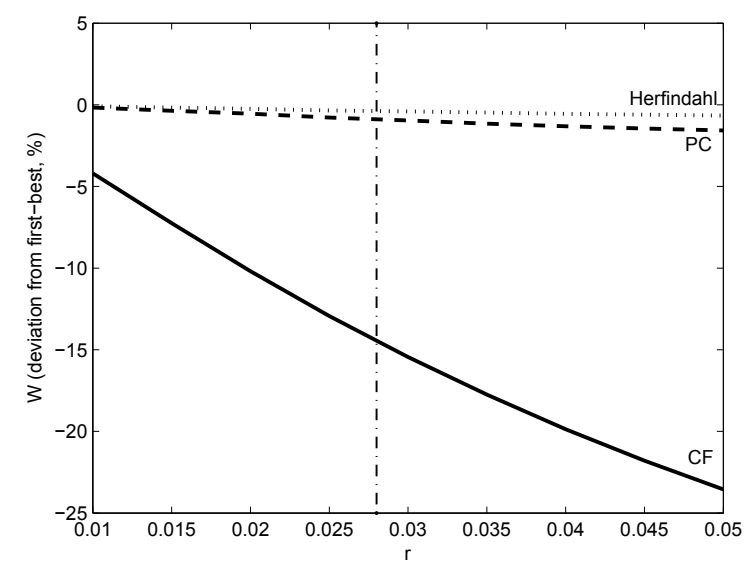

Notes: The figure shows percentage deviations of grey welfare (panel (a)), climate damage (panel (b)), and social welfare (panel (c)) from the first-best for various values of the interest rate. The solid (dashed) curves correspond to the cartel-fringe, CF (perfectly competitive, PC) equilibrium. The dotted line represents the Herfindahl scenario. Parameters are set at their benchmark values, as shown in Table 1 . The vertical lines indicate the benchmark interest rate. 


\subsection{Shale oil revolution}

Figure 6 represents the welfare and climate effects of the recent shale oil revolution, characterized by an increase in the proven reserves (left panels) and a decrease in marginal extraction costs (right panels). The shale oil revolution has increased the reserves of the rest of the world (i.e., the fringe) from 438 to 619 billion barrels (EIA, 2013), whereas the marginal extraction costs of shale oil have declined from over 100 to about 62.5 US\$/bbl (Rystad Energy, 2014; Fischer and Salant, 2017). Panel (a) shows that the increase in resource reserves would have led to higher grey welfare under perfect competition, in the first-best, and in the Herfindahl scenario. However, in the CFE, grey welfare goes down due to the sequence effect. Panel (b) shows that the increase in climate damage due to the increase in shale oil reserves is larger in the CFE than in the other scenarios. ${ }^{16}$ It can be noted from panel (c) that the shale glut has decreased social welfare, although it would have increased social welfare in the firstbest and the Herfindahl scenario. In the benchmark scenario, the addition of 181.5 billion barrels of shale oil to the reserves of the fringe has lowered social welfare by 2.8 percent. Panels (b), (d), and (f) show that the decrease in shale oil extraction costs has increased climate damage, but that grey welfare and social welfare nevertheless have increased: given the emissions factors and unit extraction costs considered, the sequence effect is not strong enough to offset the beneficial impact of the fringe's lower extraction costs.

The magnitude of the effects of the shale revolution on climate change, depends obviously on the SCC. Furthermore, the sequence effect in the CFE is crucially affected by the rate of interest: the higher the rate of interest, the more important the timing of extraction becomes for welfare. Therefore, panel (a) of Figure 7 shows combinations of the SCC (expressed in US\$) and the rate of interest for which the increase in the fringe's oil reserves (from 438 to 619.5 billion barrels) lead to an increase (grey area) and a decrease (white area) in social welfare. Similarly, panel (b) shows for which combinations of the SCC and the interest rate the fall in shale oil unit extraction costs (from 82.5 to 62.5 ) has increased social welfare. Both panels clearly show that for high values of the SCC and the rate of interest (i.e., in the upper-right corners), the shale oil revolution causes a decline in social welfare.

The main conclusion of our analysis is that almost all (97 percent) of the loss in social welfare under the cartel-fringe framework relative to the first-best is due to the inefficient order of use of the resources. Moreover, although the pure conservation effect of imperfect competition would imply 4.8 percent lower climate damages in the

\footnotetext{
${ }^{16}$ In this section, we effectively assume that the emission factor of shale oil equals the weighted average emission factor of the fringe's reserves (cf. Fischer and Salant, 2017).
} 
Figure 6: Welfare effects of the 'shale revolution'

Panel (a) - Initial stock vs. grey welfare

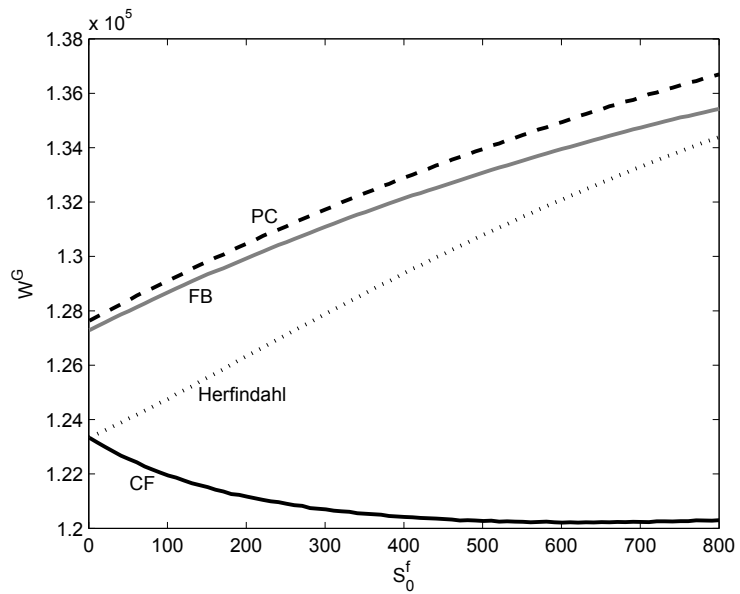

Panel (c) - Initial stock vs. damage

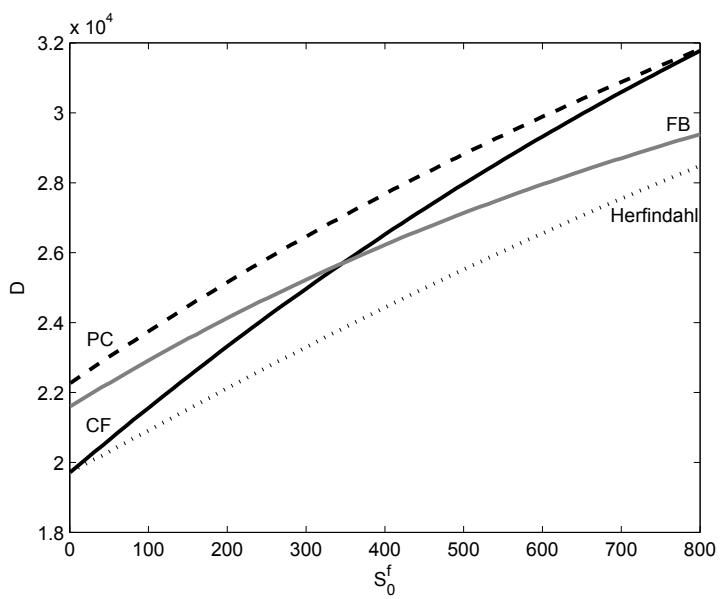

Panel (e) - Initial stock vs. social welfare

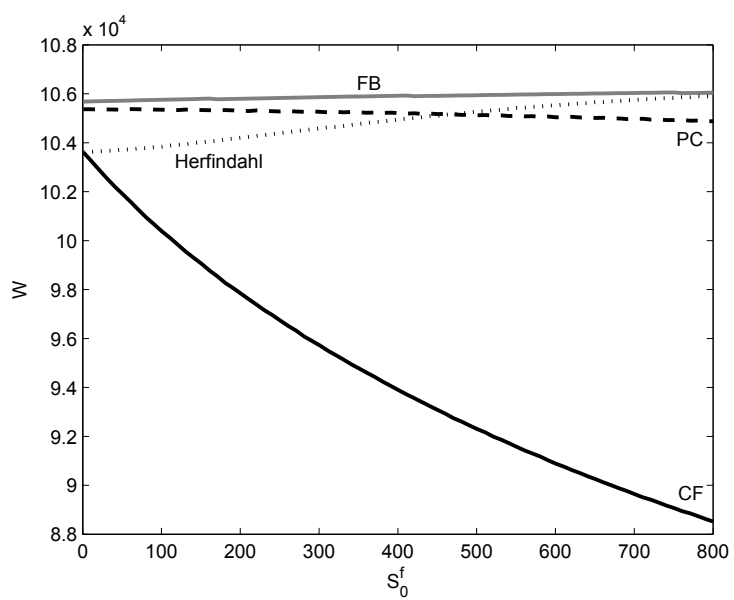

Panel (b) - Extraction costs vs. grey welfare

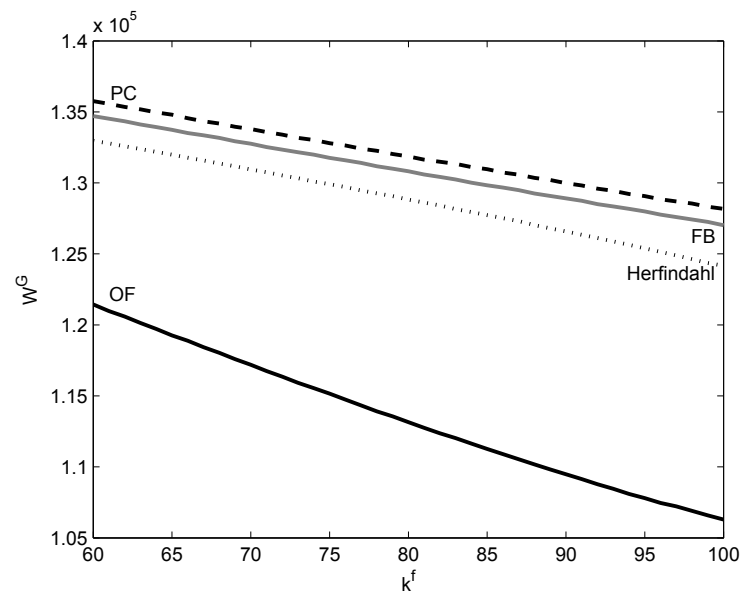

Panel (d) - Extraction costs vs. damage

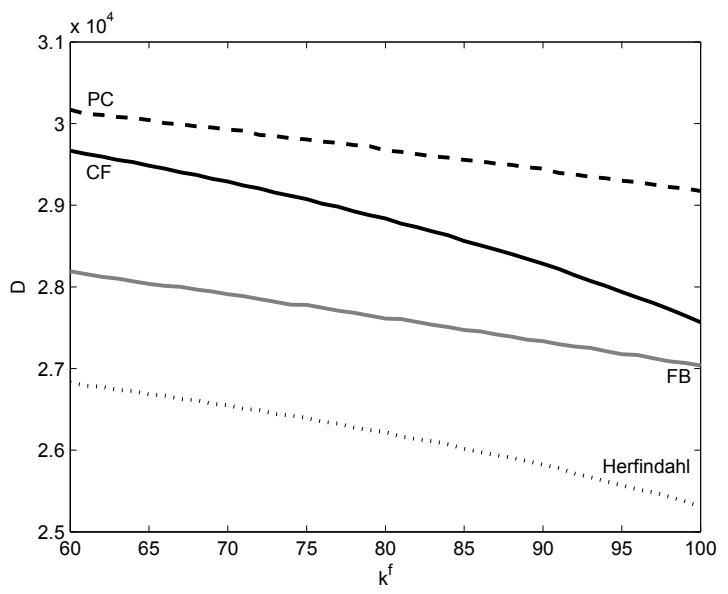

Panel (f) - Extraction costs vs. social welfare

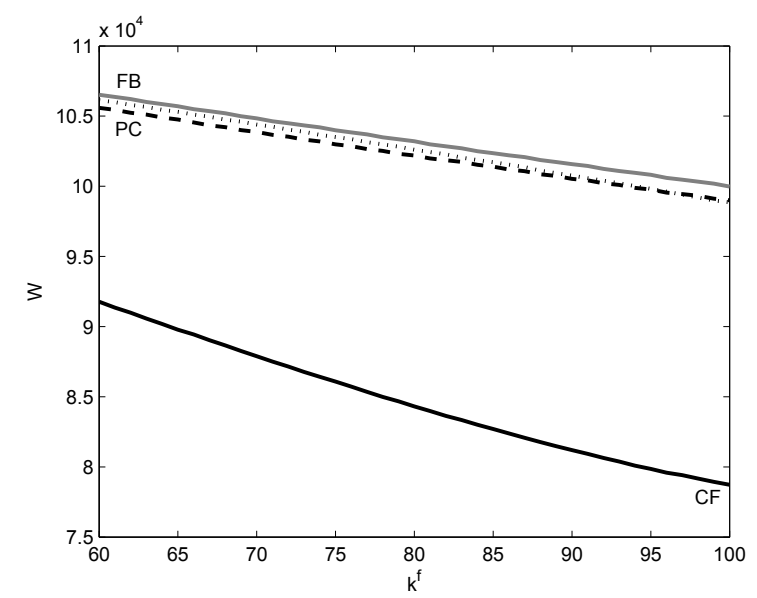

Notes: The figure shows grey welfare (panels (a) and (b)), climate damage (panels (c) and (d)) and social welfare (panels (e) and (f)) for various values of the fringe's initial resource stock and marginal extraction costs. Welfare and climate damages are expressed in US\$'s. The solid curves correspond to the cartel-fringe, CF equilibrium. The dashed black (solid grey) curves indicate the perfectly competitive equilibrium, PC (first-best outcome, FB). The dotted curves represent the Herfindahl scenario. Parameters are set at their benchmark values, as shown in Table 1 . 
Figure 7: Welfare effects of the 'shale oil revolution'

Panel (a) - Increase in shale reserves

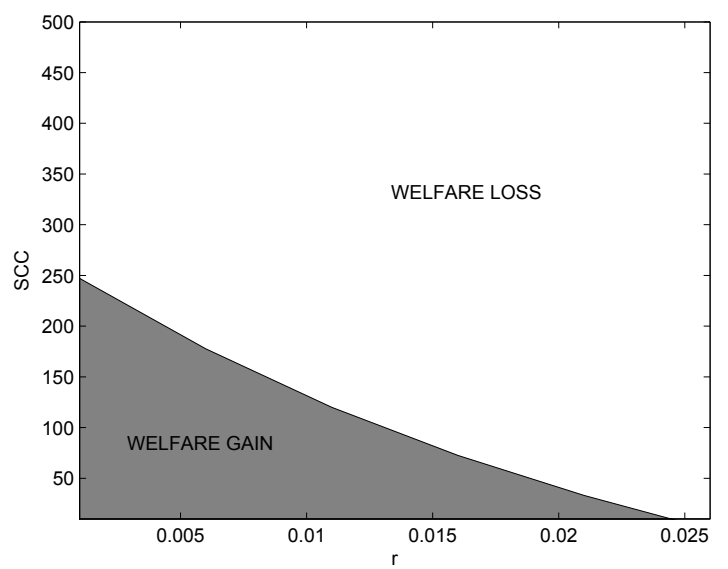

Panel (b) - Decrease in extraction costs

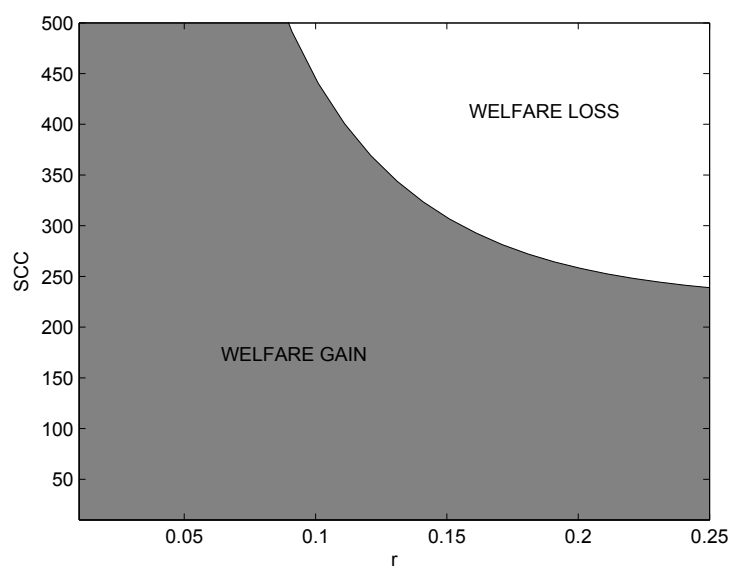

Notes: The figure shows combinations of $r$ and SCC (expressed in US\$) for which the 'shale oil revolution' has been beneficial for welfare (grey) or detrimental to welfare (white). Panel (a) shows the results for an increase in $S_{0}^{f}$ from 438 to 619.5 . Panel (b) depicts the outcomes for a decrease of $k^{f}$ from 82.5 to 62.5. Parameters are set at their benchmark values, as shown in Table 1 . For clarity reasons, the scale of the horizontal axis differs between the two panels.

CFE than in the first-best, by taking this sequence effect into account, climate damages are actually 5.3 percent larger than in the first-best. A lot of attention in the literature and the policy debate on how to address climate change evolves around ways to reduce the use of polluting resources. The merit of the policy options should be evaluated while having this important feature of the climate change problem in mind.

Below, we discuss environmental policy options while taking into account their impact on the order of use of the polluting resources.

\subsection{Green Paradox and welfare effects of environmental policy}

In this section, we first examine the effect of a renewables subsidy on the initial extraction and emission levels. ${ }^{17}$ Subsequently, we analyze the welfare and climate effects of renewables subsidies and carbon taxes. Panel (a) of Figure 8 shows that, over a range of different interest rates, a renewables subsidy equal to 10 percent of the renewables unit production cost (i.e., $\sigma=10.25$ ) increases initial output of the fringe (dashed line) -in line with the literature on the Green Paradox (Sinn, 2008, 2012)—but decreases output of the cartel (solid line). The decrease in the cartel's initial output is in line with the response of a monopolist to a renewables subsidy (Van der Meijden et al., 2015; Van der Meijden and Withagen, 2016). Panel (b) shows how the increase in initial extraction depends on the relative emission factor for the fringe. If the fringe is as polluting as the cartel, initial emissions would go up by 8.3 percent, whereas they would increase by

\footnotetext{
${ }^{17}$ We assume that the renewables subsidy remains in place after depletion at time $\bar{T}$.
} 
almost 16 percent if the fringe were twice as polluting as the cartel. In the benchmark scenario with $r=0.028$, initial emissions go up by 12 percent.

Figure 8: Renewables subsidy and the Green Paradox

Panel (a) - Initial extraction rates

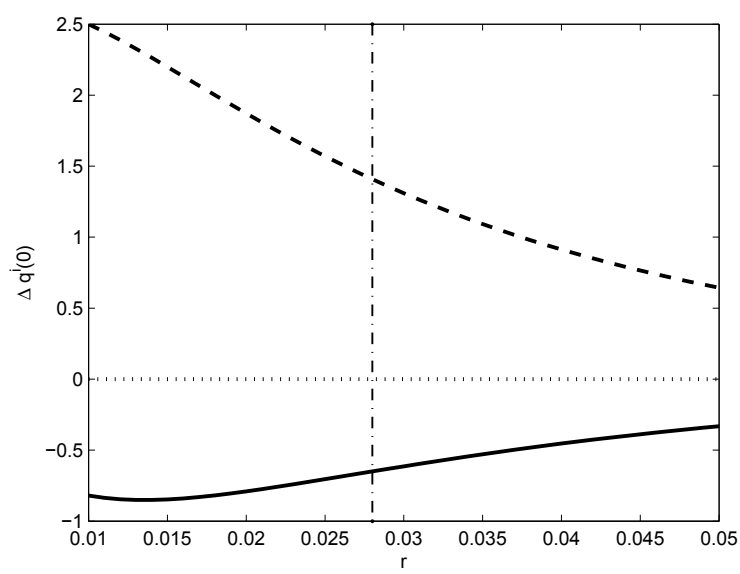

Panel (b) - Initial carbon emissions

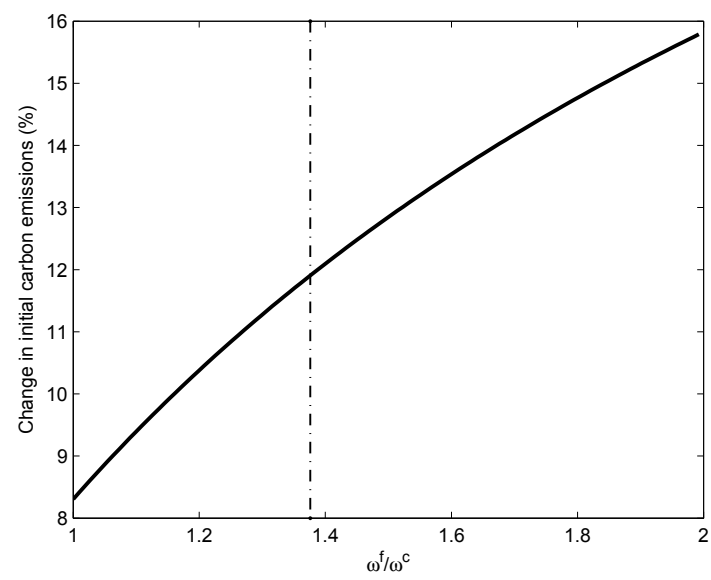

Notes: The figure shows the effect of an increase in $\sigma$ from 0 to 10.25 on the initial extraction rates for various values of the interest rate (panel (a)) and on initial emissions for various values of the relative emission factor $\omega^{f} / \omega^{c}$ (panel (b)). In panel (a), the solid line represents extraction of the cartel and the dashed line represents extraction of the fringe. Parameters are set at their benchmark values, as shown in Table 1. The vertical line in panel (a) and (b) indicates the benchmark values for the interest rate and the relative emission factor, respectively.

Figure 9 shows the effects of a renewables subsidy (panel (a)) and a carbon tax (panel (b)) on the percentage deviation of social welfare from the first-best. Panel (a) shows that a subsidy would lower welfare under perfect competition, because it speeds up resource depletion and therefore increases climate damage. In the CFE, however, a subsidy may increase social welfare, as long as the subsidy rate is small enough. The reason is that, by counteracting the conservation effect, a small renewables subsidy increases grey welfare. Panel (b) shows that a carbon tax would increase welfare under perfect competition, ${ }^{18}$ by slowing down extraction and lowering climate change. In the CFE, however, extraction is already relatively slow and the carbon tax is welfare reducing, although it reduces climate damage.

\footnotetext{
${ }^{18}$ Because extraction by the cartel and by the fringe are taxed at the same rate (so, strictly speaking, $\tau$ denotes a resource tax instead of a carbon tax), the perfectly competitive equilibrium only coincides with the first-best if emission factors of the cartel/fringe and the fringe are the same and the tax rate equals the SCC multiplied by the common emission factor. With differing emission factors, the first-best cannot be reached by imposing a resource tax. In the calibrated model, the second-best resource tax rate (i.e., the top of the dashed curve in panel (b) of Figure 9) lies between 27 and 38 US\$/bbl, the SCC of a unit of extraction by the cartel and fringe, respectively.
} 
Figure 9: Welfare effects of climate policies (percentage deviations from first-best)

Panel (a) - Renewables subsidy

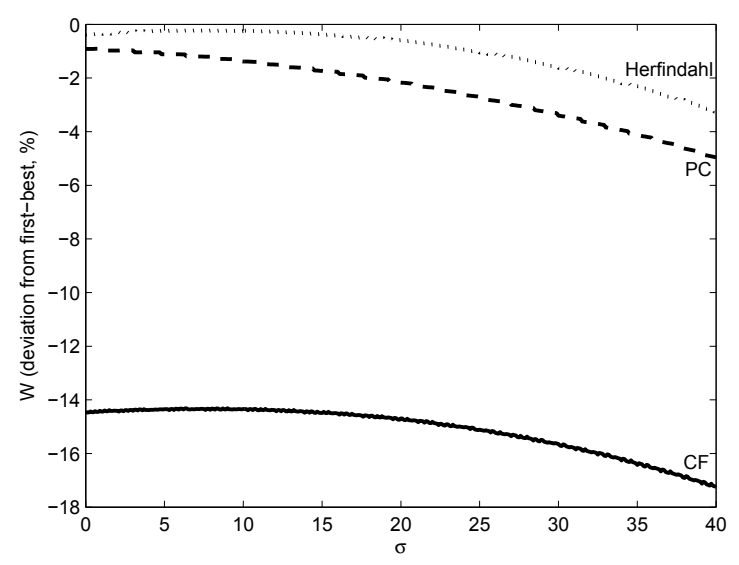

Panel (b) - Carbon tax

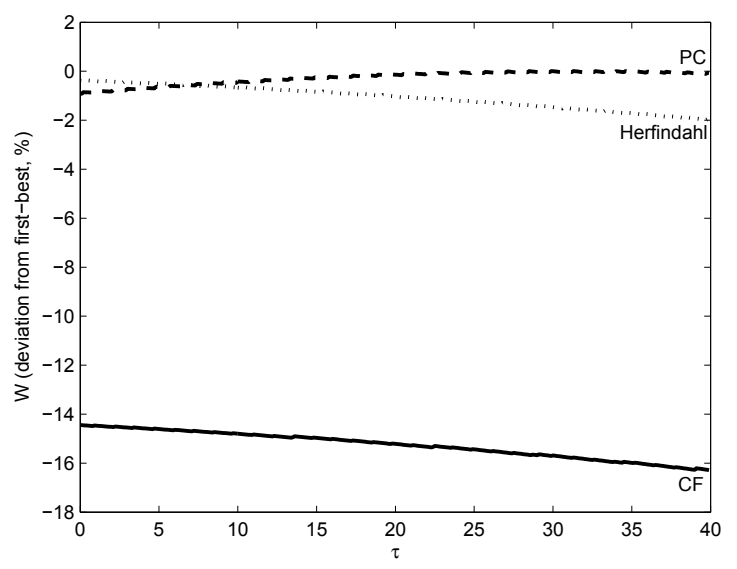

Notes: The figure shows percentage deviations of social welfare from the first-best for various values of the renewables subsidy (panel (a)) and the carbon tax rate (panel (b)). The solid (dashed) curves correspond to the cartel-fringe, CF (perfectly competitive, PC) equilibrium. The dotted curves represent to the Herfindahl scenario. Parameters are set at their benchmark values, as shown in Table 1.

\section{Conclusion}

OPEC's market power was shown to result in an inefficient order of use of the different oil reserves. A calibrated version of our model reveals that this source of inefficiency is responsible for almost the entire welfare loss of the cartel-fringe equilibrium compared to the first-best. It is also strong enough to make the recent shale oil revolution detrimental to global welfare. These distortions, which are rarely explicitly discussed during climate negotiations, could play a major role in a solution to the climate change problem. Our results were established within a model where energy needs are met by oil (owned by a cartel and a fringe) and by renewables that are perfect substitutes for oil and that can be produced in unlimited amounts by using backstop technologies.

Our analysis delivered several important new insights. First, by establishing the existence of and by fully characterizing a cartel-fringe equilibrium on the oil market, we were able to show that-in line with the current real-world situation-the cartel and the fringe start out supplying simultaneously to the market, despite their differing unit extraction costs. If the relative initial stock of the fringe is large, the phase with simultaneous supply will be followed by a phase during which only the fringe is extracting. However, if the initial stock of the cartel is relatively large, the phase with simultaneous supply will be followed by a period during which only the cartel is active. During this period, depending on its remaining resource stock and on the marginal profits at the limit price, the cartel either chooses to price strictly below the price of 
renewables, or to perform a limit-pricing strategy of just undercutting the renewables price.

Second, by decomposing the welfare and global warming consequences of imperfect competition into a conservation and a sequence effect, we demonstrated that although the monopolist may be the conservationist's friend, they will certainly not become best friends. On the one hand, the conservation effect indeed slows down climate change by increasing the initial oil price. On the other hand, imperfect competition causes front-loading in time of relatively dirty unconventional oil, which aggravates global warming. In our calibrated model, imperfect competition reduces social welfare by 14.5 percent compared to the first-best, 97 percent of which is due to the sequence effect. Furthermore, although the conservation effect lowers climate damages by 4.8 percent, by taking the sequence effect into account we find that imperfect competition on balance increases climate damages by 5.3 percent.

Third, the analysis of climate policies delivered relevant new insights. In our benchmark scenario a subsidy for renewable energy reduces current OPEC supply, but increases unconventional oil production. Hence, the average carbon content of current oil supply increases. This provides an additional channel through which announced future climate policies increase current carbon emissions. In our calibrated model, a renewables subsidy equal to 10 percent of the unit production cost of renewable energy, increases current emissions by 12 percent.

Fourth, our results also showed that the recent shale oil revolution not only increases climate damage, but also can lower grey welfare as it crowds out relatively cheap OPEC oil. If the interest rate and the social cost of carbon are large enough, the shale oil revolution causes a reduction in social welfare.

This paper is a first to attempt to examine the importance of the sequence effect that market power has on the order of use of polluting oil reserves and its repercussions on global warming. Admittedly, our results were derived within a stylized model and under a number of assumptions made for tractability or ease of exposition.

Two different streams of future research appear to be promising. The first is to examine the robustness of our conclusion under alternative scenarios. For example, alternative equilibrium concepts such as the feedback Stackelberg equilibrium, and more sophisticated dynamic climate policies are some of the important cases to examine. Introducing multiple pools with different extraction costs (Fischer and Salant, 2017), allowing for stock-dependent unit extraction costs and/or for extraction costs that are strictly convex in the quantity extracted would add more realism to our framework and would be natural extensions to consider. For example stock-dependent unit extraction costs would generate endogenous cumulative oil extraction; with extraction costs that 
are strictly convex in extraction, it is likely to have some simultaneous supply of oil and renewables. However a full-fledged analysis, beyond the scope of the present paper, is necessary to identify and eventually quantify the magnitude of a sequence effect in these cases.

The second stream of future research relates to the policy implications of the sequence effect and the conflicting interests of the different owners of oil reserves, in particular during the negotiation and the design of climate change mitigation options in a global context. While there is a successful and growing literature on strategic interactions between resource users on one-hand and resource owners on the other (e.g., Liski and Tahvonen, 2004; Harstad, 2012; Kagan et al., 2015), there is none that tackles the interactions between two (or several) groups of resource owners and resource users. Such triangular (or multilateral) interactions may well turn out to be key in reaching a sustainable solution to curbing carbon emissions. For example, inspired by Harstad (2012) and Eichner and Pethig (2017), a possible solution for the problem of inefficient order of use of resources is to allow for the possibility that resource users and owners of the 'cleaner' resource buy out the 'dirtier' reserves or compensate their owners to induce them to halt their extraction. This is obviously not a simple task; nevertheless it is definitely worth further investigation. 


\section{References}

Almoguera, P. A., C. C. Douglas And A. M. Herrera, "Testing for the cartel in OPEC: non-cooperative collusion or just non-cooperative?," Oxford Review of Economic Policy 27 (Spring 2011), 144-168.

Amigues, J.-P., P. Favard, G. Gaudet And M. Moreaux, "On the Optimal Order of Natural Resource Use When the Capacity of the Inexhaustible Substitute Is Limited," Journal of Economic Theory 80 (May 1998), 153-170.

Andrade De SÁ, S. And J. Daubanes, "Limit pricing and the (in)effectiveness of the carbon tax," Journal of Public Economics 139 (July 2016), 28-39.

Asker, J., A. Collard-WeXler And J. D. Loecker, "Market Power, Production (Mis)Allocation and OPEC," NBER Working Papers 23801, National Bureau of Economic Research, Inc, September 2017.

Benchekroun, H., A. Halsema and C. Withagen, "On nonrenewable resource oligopolies: The asymmetric case," Journal of Economic Dynamics and Control 33 (November 2009), 1867-1879.

- "When additional resource stocks reduce welfare," Journal of Environmental Economics and Management 59 (January 2010), 109-114.

Benchekroun, H. AND C. Withagen, "On price taking behavior in a nonrenewable resource cartel-fringe game," Games and Economic Behavior 76 (2012), 355-374.

BrÉmond, V., E. HACHE AND V. Mignon, "Does OPEC still exist as a cartel? An empirical investigation," Energy Economics 34 (2012), 125-131.

CAPP, "Canadian Oil and Natural Gas, http://www.capp.ca/ canadian-oil-and-natural-gas/oil-sands," Canadian Association of Petroleum Producers (2017a).

-, "Crude Oil Forecast, Markets \& Transportation - Production \& Supply Data, http://www.capp.ca/publications-and-statistics/publications/ 302698," Canadian Association of Petroleum Producers (2017b).

Chakravorty, U. AND D. L. KRUlCE, "Heterogeneous Demand and Order of Resource Extraction," Econometrica 62 (November 1994), 1445-1452.

Chakravorty, U., M. Moreaux and M. Tidball, "Ordering the Extraction of Polluting Nonrenewable Resources,” American Economic Review 98 (June 2008), 1128-1144. 
Dasgupta, P. And G. HeAl, Economic Theory and Exhaustible Resources (Cambridge Economic Handbooks, University Press, Oxford, 1979).

EIA, "Technically Recoverable Shale Oil and Shale Gas Resources: An Assessment of 137 Shale Formations in 41 Countries Outside the United States," U.S. Energy Information Administration (2013).

_- "International Energy Statistics, http://www.eia.gov/beta/international/ data/browser," U.S. Energy Information Administration (2017a).

—, "World Shale Resource Assessments, https://www.eia.gov/analysis/ studies/worldshalegas/," U.S. Energy Information Administration (2017b).

Eichner, T. And R. Pethig, "Buy coal and act strategically on the fuel market," European Economic Review 99 (2017), 77 - 92.

EPA, "Inventory of US Greenhouse Gas Emissions and Sinks," U.S. Environmental Protection Agency (2015).

FISCHER, C. AND S. W. SALANT, "Alternative climate policies and intertemporal emissions leakage," in K. Pittel, F. van der Ploeg and C. Withagen, eds., Beyond the green paradox (Cambridge, MA: MIT Press, 2014), 255-85.

- "Balancing the carbon budget for oil: The distributive effects of alternative policies," European Economic Review (2017).

Gaudet, G. And P. LAsserre, “The Efficient Use Of Multiple Sources Of A Nonrenewable Resource Under Supply Cost Uncertainty," International Economic Review 52 (02 2011), 245-258.

Gilbert, R. J., "Dominant Firm Pricing Policy in a Market for an Exhaustible Resource," Bell Journal of Economics 9 (Autumn 1978), 385-395.

Gilbert, R. J. And S. M. Goldman, "Potential competition and the monopoly price of an exhaustible resource," Journal of Economic Theory 17 (April 1978), 319-331.

Groot, F., C. Withagen And A. DE Zeeuw, "Strong time-consistency in the cartelversus-fringe model," Journal of Economic Dynamics and Control 28 (November 2003), 287-306.

Hamilton, J. D., "Causes and Consequences of the Oil Shock of 2007-08," Brookings Papers on Economic Activity 40 (2009), 215-283. 
Harstad, B., "Buy Coal! A Case for Supply-Side Environmental Policy," Journal of Political Economy 120 (2012), 77-115.

Herfindahl, O. C., "Depletion and economic theory," in M. Gaffney, ed., Extractive resources and taxation (Madison University of Wisconsin Press, 1967), 63-90.

Hozl, M., "Resource extraction, substitute production, and monopoly," Journal of Economic Theory 19 (October 1978), 28-37.

economics," Resources and Energy 5 (December 1983), 303 - 311.

- "The Supply Side of CO 2 with Country Heterogeneity," Scandinavian Journal of Economics 113 (December 2011), 846-865.

Holland, S. P., "Set-up costs and the existence of competitive equilibrium when extraction capacity is limited," Journal of Environmental Economics and Management 46 (November 2003), 539-556.

IEA, "World Energy Outlook," International Energy Agency, Paris (2013).

- " $\mathrm{CO}_{2}$ emissions from fuel combustion," International Energy Agency, Paris (2016).

Kagan, M., F. van der Ploeg and C. Withagen, "Battle for Climate and Scarcity Rents: Beyond the linear-quadratic case," OxCarre Working Papers 155, Oxford Centre for the Analysis of Resource Rich Economies, University of Oxford, December 2015.

KEMP, M. C. AND N. V. LONG, "On Two Folk Theorems Concerning the Extraction of Exhaustible Resources," Econometrica 48 (April 1980), 663-673.

KISSWANI, K., "Does OPEC act as a cartel? Empirical investigation of coordination behavior," Energy Policy 97 (2016), 171-180.

Lewis, T. R. And R. Schmalensee, “On Oligopolistic Markets for Nonrenewable Natural Resources," The Quarterly Journal of Economics 95 (1980), 475-491.

Liski, M. AND O. TAHVONEn, "Can carbon tax eat OPEC's rents?," Journal of Environmental Economics and Management 47 (January 2004), 1 - 12.

Malins, C., S. Galarza, A. Baral, A. Brandt And G. Howorth, "The Development of a Greenhouse Gas Emissions Calculation Methodology for Article 7a of the 
Fuel Quality Directive," Report to the directorate general for climate action of the european commission, Washington D.C.: The International Council on Clean Transportation (ICCT), 2014.

MCGLADE, C. AND P. EKINS, "The geographical distribution of fossil fuels unused when limiting global warming to $2^{\circ}$ C," Nature 517 (January 2015), 187-190.

Newbery, D. M. G., "Oil Prices, Cartels, and the Problem of Dynamic Inconsistency," Economic Journal 91 (September 1981), 617-46.

Nordhaus, W. D., "Revisiting the social cost of carbon," Proceedings of the National Academy of Sciences 114 (2017), 1518-1523.

OCI, "Oil Climate Index, http://oci.carnegieendowment.org/\#total-emissions," Carnegie Endowment for International Peace (2017).

OKULlo, S. J. AND F. REYNÈs, "Imperfect cartelization in $\{$ OPEC $\}$," Energy Economics 60 (2016), $333-344$.

RYSTAD ENERGY, "Global liquids cost curve, https://www.rystadenergy.com/ NewsEvents/PressReleases/global-liquids-cost-curve," Press Releases (2014).

Salant, S. W., "Staving Off the Backstop: Dynamic Limit Pricing with a Kinked Demand Curve," in R. Pindyck, ed., Advances in the Economics of Energy and Resources (Greenwich, Conn.: JAI Press, 1979).

Sinclair, P. J. N., "On the Optimum Trend of Fossil Fuel Taxation," Oxford Economic Papers 46 (1994), 869-877.

SinN, H.-W., "Public policies against global warming: a supply side approach," International Tax and Public Finance 15 (August 2008), 360-394.

- The Green Paradox: A Supply-Side Approach to Global Warming (MIT Press, Cambridge, 2012).

SOlOW, R. M. AND F. Y. WAN, "Extraction Costs in the Theory of Exhaustible Resources," Bell Journal of Economics 7 (Autumn 1976), 359-370.

Stern, N., The Economics of Climate Change: The Stern Review. (Cambridge University Press, UK, 2007).

Stiglitz, J. E., "Monopoly and the Rate of Extraction of Exhaustible Resources," The American Economic Review 66 (1976), 655-661. 
VAn Der Meijden, G., K. Ryszka And C. Withagen, "Double Limit Pricing," Tinbergen Institute Discussion Papers 15-136/VIII, Tinbergen Institute, December 2015.

VAn Der Meijden, G. And C. Withagen, "Limit pricing, climate policies and imperfect substitution," Tinbergen Institute Discussion Papers 16-089/VIII, Tinbergen Institute, December 2016.

VAN DER Ploeg, F., "Second-best carbon taxation in the global economy: The Green Paradox and carbon leakage revisited," Journal of Environmental Economics and Management 78 (2016), 85-105.

Van der Ploeg, F. And C. Withagen, "Global Warming and the Green Paradox: A Review of Adverse Effects of Climate Policies," Review of Environmental Economics and Policy 9 (2015), 285-303.

U.S. Department of the TREAsury, "Daily Treasury Long Term Rate Data, https://www.treasury.gov/resource-center/data-chart-center/ interest-rates/Pages/TextView.aspx?data=longtermrate," Department of the Treasury (2017).

Withagen, C., "Cartel-versus-Fringe Models," in J. F. Shogren, ed., Encyclopedia of Energy, Natural Resource, and Environmental Economics (Waltham: Elsevier, 2013), $260-267$. 


\section{Appendix}

Throughout this Appendix, we will refer to the stock sizes $S_{0 S}^{c}, \hat{S}_{0}^{c}$ and $\hat{S}_{L}$, and extraction durations $T_{S}, \hat{T}_{S}$ and $\hat{\Delta}$, which are defined in the main text and are, for convenience, restated here:

- For each $S_{0}^{f}$ there exists a unique $S_{0 S}^{c}$ such that the equilibrium reads $S$. The unique duration of this $S$-phase is denoted by $T_{S}$ (see Lemma 4).

- If $\hat{\pi}>0$, then for each $S_{0}^{f}$, there exists a unique $\hat{S}_{0}^{c}$ such that the equilibrium reads $S \rightarrow \hat{L}$. The duration of the $S$-phase is denoted by $\hat{T}_{S}$, the duration of limit pricing is $\hat{\Delta}$, and the cumulative extraction during limit pricing is $\hat{S}_{L}$ (see Lemma 7).

\section{A Proofs of Lemmata 2-3 and 5-10 and Propositions 2-3}

The proofs in this section will make use of Lemma A.1, Lemma A.2, and Lemma A.3 below.

Lemma A.1 Suppose the equilibrium reads $S \rightarrow F$ with transition at $T_{S}$ and final time $T_{F}$. Then

$$
\begin{aligned}
r \beta S_{0}^{f}= & -\left(k^{f}-k^{c}\right)\left(r T_{S}-1+e^{-r T_{S}}\right)+\left(\hat{b}-k^{f}\right)\left(r T_{F}-1+e^{-r T_{F}}\right) \\
& +(\alpha-\tau-\hat{b}) r T_{F}, \\
r \beta S_{0}^{c}= & \left(k^{f}-k^{c}\right)\left(r T_{S}-1+e^{-r T_{S}}\right) .
\end{aligned}
$$

Proof. Along $S$ we have (12c) and (12d). Along $F$ we have (11c). Furthermore $\lambda^{f}=\left(\hat{b}-k^{f}\right) e^{-r T_{F}}$. Also $\lambda^{c}=\left(k^{f}-k^{c}\right) e^{-r T_{S}}+\lambda^{f}=\left(k^{f}-k^{c}\right) e^{-r T_{S}}+\left(\hat{b}-k^{f}\right) e^{-r T_{F}}$. Taking the time integrals of $q^{f}$ and $q^{c}$ yields the result.

Lemma A.2 Suppose the equilibrium reads $S \rightarrow \tilde{L}$ with transition at $\tilde{T}_{S}$ and final time $\tilde{T}_{L}$. Then

$$
\begin{aligned}
r \beta S_{0}^{f}= & \left(\alpha-\tau+k^{c}-2 k^{f}\right) r \tilde{T}_{S}-\left(\hat{b}-k^{c}\right) e^{-r \tilde{T}_{L}}\left(1-e^{r \tilde{T}_{S}}\right) \\
& -2\left(\hat{b}-k^{f}\right)\left(1-e^{-r \tilde{T}_{S}}\right), \\
r \beta S_{0}^{c}= & \left.\left(k^{f}-k^{c}\right) r \tilde{T}_{S}+\hat{b}-k^{f}\right)\left(1-e^{-r \tilde{T}_{S}}\right)+\left(\hat{b}-k^{c}\right) e^{-r \tilde{T}_{L}}\left(1-e^{r \tilde{T}_{S}}\right) \\
& +(\alpha-\tau-\hat{b}) r\left(\tilde{T}_{L}-\tilde{T}_{S}\right) .
\end{aligned}
$$


Proof. Along $S$ we have (12c) and (12d). Along the $\tilde{L}$-phase we have (14b). It follows from (10) that $\lambda^{c}=\left(\hat{b}-k^{c}\right) e^{-r \tilde{T}_{L}}$. It follows from (12a) together with price continuity that $\lambda^{f}=\left(\hat{b}-k^{f}\right) e^{-r \tilde{T}_{S}}$. Taking the time integrals of $q^{f}$ and $q^{c}$ yields the result.

Note that the Hamiltonian is discontinuous at $\tilde{T}_{S}$ if the initial stocks differ from those in Lemma 6: $q^{c}$ and $\mu$ jumps upward $\tilde{T}_{S}$, while $q^{f}$ jumps downward.

Lemma A.3 Suppose the equilibrium reads $S \rightarrow C \rightarrow \hat{L}$ with transitions at $\bar{T}_{S}$ and $\bar{T}_{C}$ and final time $\bar{T}_{L}$. Then

$$
\begin{aligned}
r \beta S_{0}^{f}= & \left(\alpha-\tau+k^{c}-2 k^{f}\right)\left(r \bar{T}_{S}-1+e^{-r \bar{T}_{S}}\right) \\
r \beta S_{0}^{c}= & \frac{1}{2}\left(2 k^{f}-k^{c}-\alpha+\tau\right)\left(r \bar{T}_{S}-1+e^{-r \bar{T}_{S}}\right) \\
& +\frac{1}{2}\left(2 \hat{b}-k^{c}-\alpha+\tau\right)\left(r \bar{T}_{C}-1+e^{-r \bar{T}_{C}}\right) \\
& +(\alpha-\tau-\hat{b}) r \bar{T}_{L} \\
\left(\hat{b}-k^{c}\right) e^{-r \bar{T}_{L}}= & {\left[2 \hat{b}-\alpha+\tau-k^{c}\right] e^{-r \bar{T}_{C}} . }
\end{aligned}
$$

Proof. Along $S$ we have (12c) and (12d). Along the $C$-phase we have (13c). Along the $\hat{L}$-phase we have (14b). Moreover, we have $\lambda^{c}=\left(\hat{b}-k^{c}\right) e^{-r \bar{T}_{L}}$. The price is continuous at $\bar{T}_{S}$ so that

$$
k^{f}+\lambda^{f} e^{r \bar{T}_{S}}=\frac{1}{2}\left(\alpha-\tau+k^{c}+\lambda^{c} e^{r \bar{T}_{S}}\right) .
$$

Condition (A.3c) is obtained by combining (9b) and (10) and using price continuity at $t=\bar{T}_{C}$. Taking the time integrals of $q^{f}$ and $q^{c}$ yields the result.

\section{A.1 Proof of Lemma 2}

Part (i). Given our definition of $C$ and $F$ a transition can only take place at a moment $T$ where the producer price is below $\hat{b}$. Indeed, in an equilibrium the producer price is increasing in both phases and must therefore be smaller than $\hat{b}$ The price is continuous at $T$ :

$$
\begin{aligned}
p(T) & =\alpha-\beta\left(q^{f}(T)+q^{c}(T)\right)=k^{f}+\lambda^{f} e^{r T} \\
& \left.=\frac{1}{2}\left(\alpha-\tau+k^{c}+\lambda^{c} e^{r T}\right)\right) .
\end{aligned}
$$

If we have $F \rightarrow C$ then it follows from (11a) and (11b) that $k^{f}+\lambda^{f} e^{r T} \leq k^{c}+\lambda^{c} e^{r T}$. Hence $\left[2\left(k^{f}+\lambda^{f} e^{r T}\right)-\alpha+\tau\right] \geq k^{f}+\lambda^{f} e^{r T}$, implying $p(T) \geq \alpha-\tau$, a contradiction. The proof for $C \rightarrow F$ is similar. 
Part (ii). Suppose it is optimal to have $F \rightarrow \hat{L}$ or $F \rightarrow \tilde{L}$ and assume the transition takes place at $T$. Then for $0 \leq t \leq T$ we have

$$
q^{f}(t)=\frac{\alpha-\tau-k^{f}-\lambda^{f} e^{r t}}{\beta}, q^{f}(T)=\frac{\alpha-\tau-\hat{b}}{\beta}
$$

because of price continuity. Hence:

$$
\begin{aligned}
\hat{b}-k^{f} & =\lambda^{f} e^{r T}, \\
q^{f}(t) & =\frac{\alpha-\tau-k^{f}-\left(\hat{b}-k^{f}\right) e^{r t-r T}}{\beta} .
\end{aligned}
$$

The cartel should not want to supply before $T$ so that for $0 \leq t \leq T$ we have

$$
\alpha-\tau-\beta\left[\frac{\alpha-\tau-k^{f}-\left(\hat{b}-k^{f}\right) e^{r(t-T)}}{\beta}\right] \leq k^{c}+\lambda^{c} e^{r t}=k^{c}+\left(\hat{b}-k^{c}\right) e^{r\left(t-T^{c}\right)},
$$

from (10), or $k^{f}\left(1-e^{r(t-T)}\right)-k^{c}\left(1-e^{r\left(t-T^{c}\right)}\right) \leq \hat{b} e^{r t-r T^{c}}\left(1-e^{r\left(T^{c}-T\right)}\right)$. Take the limit for $t$ approaching $T$. Then the condition boils down to $\left(\hat{b}-k^{c}\right)\left(1-e^{r\left(T-T^{c}\right)}\right) \leq 0$, a contradiction.

Part (iii). Along $F$ we have $k^{f}+\lambda^{f} e^{r t} \leq k^{c}+\lambda^{c} e^{r t}$, which implies $k^{f}-k^{c} \leq\left(\lambda^{c}-\lambda^{f}\right) e^{r t}$. At the transition from $F$ to $S$ at say $T$ we have from the continuity of the price $k^{f}-k^{c}=$ $\left(\lambda^{c}-\lambda^{f}\right) e^{r t}$. Because we have assumed $k^{f}>k^{c}$, the left-hand sides of the latter two expressions are positive. Hence, the right-hand side of these expressions is growing over time. However, since $F$ precedes $S,\left(\lambda^{c}-\lambda^{f}\right) e^{r t}$ is larger than $k^{f}-k^{c}$ before $T$ and equal to $k^{f}-k^{c}$ at $T$. Hence, the right-hand sides must be declining, which yields a contradiction.

Part (iv). Suppose the initial regime is $C$. Then it follows from (13a) and (13b) that along $C$ we have $\alpha-\tau+k^{c}-2 k^{f} \leq\left(2 \lambda^{f}-\lambda^{c}\right) e^{r T}$. There is no transition possible to $F$. Hence there must be a transition to $S$, say at $T$. So $\alpha-\tau+k^{c}-2 k^{f}=\left(2 \lambda^{f}-\lambda^{c}\right) e^{r T}$. Since $\alpha-\tau+k^{c}-2 k^{f}>0$ by assumption and $C$ starts at time 0 , we have $2 \lambda^{f}-\lambda^{c}>0$, so that $\left(2 \lambda^{f}-\lambda^{c}\right) e^{r t}$ is increasing over time, yielding a contradiction.

\section{A.2 Proof of Lemma 3}

Along $S$ we have (12c) and (12d). Moreover, $\lambda^{c}=\left(\hat{b}-k^{c}\right) e^{-r T_{S}}$ and $p\left(T_{S}\right)=\alpha-$ $\beta\left(q^{f}\left(T_{S}\right)+q^{c}\left(T_{S}\right)\right)=\hat{b}$ so that $\lambda^{f}=\left(\hat{b}-k^{f}\right) e^{-r T_{S}}$. Taking the time integrals of $q^{f}$ and $q^{c}$ yields the result. 


\section{A.3 Proof of Lemma 5}

First rewrite the system (A.1a) and (A.1b) as

$$
\begin{aligned}
& \mathbf{F}\left(T_{S}, T_{F}\right)=0 \\
& \mathbf{G}\left(T_{S}, T_{F}\right)=0
\end{aligned}
$$

where

$$
\begin{aligned}
\mathbf{F}\left(T_{S}, T_{F}\right) \equiv & -\left(k^{f}-k^{c}\right)\left(r T_{S}-1+e^{-r T_{S}}\right)+\left(\hat{b}-k^{f}\right)\left(r T_{F}-1+e^{-r T}\right) \\
& +(\alpha-\tau-\hat{b}) r T_{F}-r \beta S_{0}^{f} \\
\mathbf{G}\left(T_{S}, T_{F}\right) \equiv & \left(k^{f}-k^{c}\right)\left(r T_{S}-1+e^{-r T_{S}}\right)-r \beta S_{0}^{c}
\end{aligned}
$$

Given $S_{0}^{c}$, if the equilibrium reads $S \rightarrow F$ then the transition time $T_{S}$ denotes the duration of the equilibrium the equilibrium that reads $S$.

Now given $T_{S}$, is there a solution $T_{F} \geq T_{S}$ that solves $\mathbf{F}\left(T_{S}, T_{F}\right)=0$ ? When $S_{0}^{f}=$ $S_{0 S}^{f}$ we have $\mathbf{F}\left(T_{S}, T_{S}\right)=0$, so when $S_{0}^{f}>S_{0 S}^{f}$ we get $\mathbf{F}\left(T_{S}, T_{S}\right)<0$. We derive

$$
\begin{aligned}
\mathbf{F}_{T} & =r\left(\left(\hat{b}-k^{f}\right)\left(1-e^{-r T_{F}}\right)+(\alpha-\tau-\hat{b})\right)>0, \\
\mathbf{F}_{T T} & =r^{2}\left(\hat{b}-k^{f}\right) e^{-r T_{F}}>0 .
\end{aligned}
$$

Hence, $\mathbf{F}$ is monotonically increasing and strictly convex in $T_{F}$. As a result, there exists at most one $T_{F}$ that solves $\mathbf{F}\left(T_{S}, T_{F}\right)=0$ with $T_{F}>T_{S}$. Such a solution exists if

$$
\lim _{T \rightarrow \infty} \mathbf{F}\left(T_{S}, T_{F}\right)>0
$$

We have $\lim _{T \rightarrow \infty} \mathbf{F}\left(T_{S}, T_{F}\right)=\lim _{T_{F} \rightarrow \infty}\left(\hat{b}-k^{f}+\alpha-\tau-b\right) r T_{F}=\infty$.

\section{A.4 Proof of Lemma 6}

Along $S$ we have (12c) and (12d). Along the $\hat{L}$-phase we have (14b). It follows from (12a) that $\lambda^{f}=\left(\hat{b}-k^{f}\right) e^{-r \hat{T}_{S}}$. It follows from (12b) and continuity of the price and the Hamiltonian of the cartel that $\lambda^{c}=\left[2 \hat{b}-\alpha+\tau-k^{c}\right] e^{-r \hat{T}_{S}}$. Condition (18c) is obtained by combining (9b) and (10). Taking the time integrals of $q^{f}$ and $q^{c}$ yields the result. 


\section{A.5 Proof of Lemma 7}

Given $S_{0}^{f}$ there exists a unique $T$ denoted $\hat{T}_{S}$ that satisfies

$$
r \beta S_{0}^{f}=\left(\alpha-\tau+k^{c}-2 k^{f}\right)\left(r T-1+e^{-r T}\right)
$$

Next, we establish that $\hat{T}_{S}>T_{S}$. Note from (17a)-(17b) that $T_{S}$ is the solution to

$$
\begin{aligned}
r \beta S_{0}^{f} & =\left(\hat{b}+k^{c}-2 k^{f}\right)\left(r T_{S}-1+e^{-r T_{S}}\right)+(\alpha-\tau-\hat{b}) r T_{S} \\
& =\left(\alpha-\tau+k^{c}-2 k^{f}\right)\left(r T_{S}-1+e^{-r T_{S}}\right)+(\alpha-\tau-\hat{b})\left(1-e^{-r T_{S}}\right) .
\end{aligned}
$$

Let $\mathbf{f}(T) \equiv\left(\alpha-\tau+k^{c}-2 k^{f}\right)\left(r T-1+e^{-r T}\right)$. We have $\mathbf{f}^{\prime}>0$ and $\mathbf{f}\left(\hat{T}_{S}\right)=\mathbf{f}\left(T_{S}\right)+$ $(\alpha-\tau-\hat{b})\left(1-e^{-r T_{S}}\right)>\mathbf{f}\left(T_{S}\right)$, implying $\hat{T}_{S}>T_{S}$.

We now argue that there exist $\hat{T}^{L}=\hat{T}_{S}+\hat{\Delta}$ and $\hat{S}_{0}^{c}>S_{0 S}^{c}+\hat{S}_{L}$ which satisfy (18b) and (18c):

$$
\begin{aligned}
r \beta \hat{S}_{0}^{c}= & \left.\left(\hat{b}-\alpha+\tau+k^{f}-k^{c}\right)\right)\left(r \hat{T}_{S}-1+e^{-r \hat{T}_{S}}\right) \\
& +(\alpha-\tau-\hat{b}) r\left(\hat{T}_{S}+\hat{\Delta}\right), \\
\left(\hat{b}-k^{c}\right) e^{-r \hat{\Delta}}= & \left.2 \hat{b}-\alpha+\tau-k^{c}\right) .
\end{aligned}
$$

Condition (18c) is satisfied by definition of $\hat{\Delta}$.

The rest of the proof consists of showing that the stock given by (A.7a), $\hat{S}_{0}^{c}$, is larger than $S_{0 S}+\hat{S}_{L}$. Using the definition of $\hat{S}_{L}$, (A.7a) becomes

$$
\left.r \beta\left(\hat{S}_{0}^{c}-\hat{S}_{L}\right)=\left(\hat{b}-(\alpha-\tau)+k^{f}-k^{c}\right)\right)\left(r \hat{T}_{S}-1+e^{-r \hat{T}_{S}}\right)+(\alpha-\tau-\hat{b}) r \hat{T}_{S}
$$

Summing (18a) with $T=\hat{T}_{S}$ and (A.8) yields

$$
\begin{aligned}
r \beta\left(\hat{S}_{0}^{c}-\hat{S}_{L}+S_{0}^{f}\right)= & \left(\alpha-\tau+k^{c}-2 k^{f}\right)\left(r \hat{T}_{S}-1+e^{-r \hat{T}_{S}}\right) \\
& \left.+\left(\hat{b}-\alpha+\tau+k^{f}-k^{c}\right)\right)\left(r \hat{T}_{S}-1+e^{-r \hat{T}_{S}}\right) \\
& +(\alpha-\tau-\hat{b}) r \hat{T}_{S}, \\
= & \left(\hat{b}-k^{f}\right)\left(r \hat{T}_{S}-1+e^{-r \hat{T}_{S}}\right)+(\alpha-\tau-\hat{b}) r \hat{T}_{S}, \\
= & \left(\hat{b}-k^{f}\right) \mathbf{g}\left(\hat{T}_{S}\right)+(\alpha-\tau-\hat{b}) r \hat{T}_{S},
\end{aligned}
$$

where $\mathbf{g}(T) \equiv r T-1+e^{-r T}$. By definition of $S_{0 S}^{c}$ we have

$$
\begin{aligned}
r \beta S_{0}^{f} & =\left(\hat{b}+k^{c}-2 k^{f}\right)\left(r T_{S}-1+e^{-r T_{S}}\right)+(\alpha-\tau-\hat{b}) r T_{S}, \\
r \beta S_{0 S}^{c} & =\left(k^{f}-k^{c}\right)\left(r T_{S}-1+e^{-r T_{S}}\right) .
\end{aligned}
$$


Summing (A.10a) and (A.10b) gives

$$
\begin{aligned}
r \beta\left(S_{0 S}^{c}+S_{0}^{f}\right) & =\left(\hat{b}-k^{f}\right)\left(r T_{S}-1+e^{-r T_{S}}\right)+(\alpha-\tau-\hat{b}) r T_{S} \\
& =\left(\hat{b}-k^{f}\right) g\left(T_{S}\right)+(\alpha-\tau-\hat{b}) r T_{S} .
\end{aligned}
$$

Since $\mathbf{g}(T)+(\alpha-b) r T$ is increasing in $T$ and since $\hat{T}_{S}>T_{S}$, we have from (A.9) and (A.11) $r \beta\left(S_{0 S}^{c}+S_{0}^{f}\right)<r \beta\left(\hat{S}_{0}^{c}-\hat{S}_{L}+S_{0}^{f}\right)$, implying $\hat{S}_{0}^{c}>S_{0 S}^{c}+\hat{S}_{L}$.

\section{A.6 Proof of Lemma 8}

We need to show that there exist $\bar{T}_{S}$ and $\bar{T}_{C}$ such that the system (A.3a)-(A.3c) holds, where $\bar{T}_{L}=\bar{T}_{C}+\hat{T}_{L M}$. Note that given $S_{0}^{f}$ the solution to $r \beta S_{0}^{f}=\left(\alpha-\tau+k^{c}-2 k^{f}\right)(r T-$ $\left.1+e^{-r T}\right)$ is unique and therefore $\bar{T}_{S}$ is the same as the duration of the $S$ phase when $S_{0}^{c}=S_{0 S}^{c}+\hat{S}_{L}$ that is when the regime reads $S \rightarrow \hat{L}$. Hence, $\bar{T}_{S}=\hat{T}_{S}$.

The proof now consists of showing that there exists $\bar{T}_{C}$ that solves

$$
\begin{aligned}
\mathbf{Y}\left(\bar{T}_{C}\right) \equiv & -r \beta S_{0}^{c}+\frac{1}{2}\left(2 k^{f}-k^{c}-\alpha+\tau\right)\left(r \bar{T}_{S}-1+e^{-r \bar{T}_{S}}\right) \\
& +\frac{1}{2}\left(2 \hat{b}-k^{c}-\alpha+\tau\right)\left(r \bar{T}_{C}-1+e^{-r \bar{T}_{C}}\right) \\
& +(\alpha-\tau-\hat{b}) r \bar{T}_{L}=0
\end{aligned}
$$

We know that $\mathbf{Y}\left(\bar{T}_{S}\right)<0$ for $S_{0}^{c}>\hat{S}_{0}^{c}$ since $\mathbf{Y}\left(\bar{T}_{S}\right)=0$ when $S_{0}^{c}=\hat{S}_{0}^{c}$. Moreover, we have $\lim _{\bar{T}_{C} \rightarrow \infty} \mathbf{Y}\left(\bar{T}_{C}\right)=\infty$ and $\mathbf{Y}^{\prime}>0$, which implies the existence and unicity of $\bar{T}_{C}$ that solves $\mathbf{Y}\left(\bar{T}_{C}\right)=0$.

\section{A.7 Proof of Lemma 9}

To prove Lemma 9 it will be useful to make the following two remarks.

Remark 1 Given $S_{0}^{f}$, when $S_{0}^{c}$ approaches $S_{0 S}^{c}$ from above, $\tilde{T}_{L}$ and $\tilde{T}_{S}$ approach $T_{S}$ : the $\tilde{L}$ collapses. Indeed simple substitution of $S_{0}^{c}$ by $S_{0 S}^{c}$, $\tilde{T}_{S}$ by $T_{S}$ and $\tilde{T}_{L}$ by $T_{S}$ shows that the system (A.2a)-(A.2b) becomes after simplification

$$
\begin{aligned}
r \beta S_{0}^{f} & =\left(\hat{b}+k^{c}-2 k^{f}\right)\left(r T_{S}-1+e^{-r T_{S}}\right)+(\alpha-\tau-\hat{b}) r T_{S}, \\
r \beta S_{0 S}^{c} & =\left(k^{f}-k^{c}\right)\left(r T_{S}-1+e^{-r T_{S}}\right),
\end{aligned}
$$

which holds by definition of $T_{S}$ and $S_{0 S}^{c}$ (see Lemma 3). 
Remark 2 Given $S_{0}^{f}$, when $S_{0}^{c}=\hat{S}_{0}^{c}$ we have $\tilde{T}_{S}=\hat{T}_{S}$ and $\tilde{T}_{L}=\hat{T}_{S}+\hat{\Delta}$ : the length of $\tilde{L}$ equals the length of $\hat{L}$. Indeed simple substitution of these three equalities in (A.2a)-(A.2b) and using (18c) gives

$$
\begin{aligned}
r \beta S_{0}^{f}= & \left(\alpha-\tau+k^{c}-2 k^{f}\right)\left(r \hat{T}_{S}-1+e^{-r \hat{T}_{S}}\right), \\
r \beta \hat{S}_{0}^{c}= & \left.\left(\hat{b}-\alpha+\tau+k^{f}-k^{c}\right)\right)\left(r \hat{T}_{S}-1+e^{-r \hat{T}_{S}}\right) \\
& +(\alpha-\tau-\hat{b}) r\left(\hat{T}_{S}+\hat{\Delta}\right), \\
\left(\hat{b}-k^{c}\right) e^{-r\left(\hat{T}_{S}+\hat{\Delta}\right)}= & {\left[2 \hat{b}-(\alpha-\tau)-k^{c}\right] e^{-r \hat{T}_{S}} . }
\end{aligned}
$$

which holds by definition of $\hat{T}_{S}, \hat{\Delta}$, and $\hat{S}_{0}^{c}$ (see Lemma 6 and Lemma 7).

The proof of Lemma 9 makes use of the remarks above. It consists of showing that for any $S_{0}^{f}$ and for any $S_{0}^{c} \in\left[S_{0 S}^{c}, \hat{S}_{0}^{c}\right]$ there exists $\tilde{T}_{S}$ and $\tilde{T}_{L} \geq \tilde{T}_{S}$ such that (A.2a) and (A.2b) are satisfied. The sum of (A.2a) and (A.2b) reads

$$
r \beta\left(S_{0}^{f}+S_{0}^{c}-\frac{\alpha-\tau-\hat{b}}{\beta}\left(\tilde{T}_{L}-\tilde{T}_{S}\right)\right)=\left(\alpha-\tau-k^{f}\right) r \tilde{T}_{S}-\left(\hat{b}-k^{f}\right)\left(1-e^{-r \tilde{T}_{S}}\right) .
$$

Condition (A.15) defines a unique relationship between the duration of limit pricing $\tilde{T}_{L}-\tilde{T}_{S}$ and the time of transition (or duration of the $S$ phase); we rewrite this condition as

$$
\tilde{T}_{L}-\tilde{T}_{S}=\mathbf{H}\left(\tilde{T}_{S}, S_{0}^{f}, S_{0}^{c}\right) \equiv \frac{r \beta\left(S_{0}^{f}+S_{0}^{c}\right)-\left(\alpha-\tau-k^{f}\right) r \tilde{T}_{S}+\left(\hat{b}-k^{f}\right)\left(1-e^{-r \tilde{T}_{S}}\right)}{(\alpha-\tau-\hat{b}) r}
$$

Manipulations allow to rewrite (A.2a) as $e^{r\left(\tilde{T}_{L}-\tilde{T}_{S}\right)}=\mathbf{Z}\left(\tilde{T}_{S}, S_{0}^{f}\right)$, with

$$
\mathbf{Z}\left(\tilde{T}_{S}, S_{0}^{f}\right) \equiv \frac{\left(\hat{b}-k^{c}\right)\left(1-e^{-r \tilde{T}_{S}}\right)}{r \beta S_{0}^{f}+2\left(\hat{b}-k^{f}\right)\left(1-e^{-r \tilde{T}_{S}}\right)-\left(\alpha-\tau+k^{c}-2 k^{f}\right) r \tilde{T}_{S}} .
$$

Substituting $\tilde{T}_{L}-\tilde{T}_{S}=\mathbf{H}\left(\tilde{T}_{S}, S_{0}^{f}, S_{0}^{c}\right)$ allows us to characterize $\tilde{T}_{S}$ as the solution to

$$
\mathbf{W}\left(\tilde{T}_{S}, S_{0}^{f}, S_{0}^{c}\right)=0, \text { with } \mathbf{W}\left(\tilde{T}_{S}, S_{0}^{f}, S_{0}^{c}\right) \equiv e^{\mathbf{H}\left(\tilde{T}_{S}, S_{0}^{f}, S_{0}^{c}\right)}-\mathbf{Z}\left(\tilde{T}_{S}, S_{0}^{f}\right)
$$

We argue that, given $S_{0}^{f}$, for any $S_{0}^{c} \in\left[S_{0 S}^{c}, \hat{S}_{0 S}^{c}\right]$ there exists a solution $\tilde{T}_{S}$ to (A.18). From Remark 1 and Remark 2 above we get

$$
\mathbf{W}\left(T_{S}, S_{0}^{f}, S_{0 S}^{c}\right)=0=\mathbf{W}\left(\hat{T}_{S}, S_{0}^{f}, \hat{S}_{0 S}^{c}\right)
$$


As $\mathbf{W}\left(\tilde{T}_{S}, S_{0}^{f}, S_{0}^{c}\right)$ is an increasing function of $S_{0}^{c}$, we have for any $S_{0}^{c} \in\left(S_{0 S}^{c}, \hat{S}_{0 S}^{c}\right)$

$$
\begin{aligned}
& \mathbf{W}\left(T_{S}, S_{0}^{f}, S_{0}^{c}\right)>\mathbf{W}\left(T_{S}, S_{0}^{f}, S_{0 S}^{c}\right)=0 \\
& \mathbf{W}\left(\hat{T}_{S}, S_{0}^{f}, S_{0}^{c}\right)<\mathbf{W}\left(\hat{T}_{S}, S_{0}^{f}, \hat{S}_{0 S}^{c}\right)=0 .
\end{aligned}
$$

Since $\mathbf{W}\left(\tilde{T}_{S}, S_{0}^{f}, S_{0}^{c}\right)$ is a continuous function of $\tilde{T}_{S}$ we can therefore state that for any $S_{0}^{c} \in\left[S_{0 S}^{c}, \hat{S}_{0 S}^{c}\right]$ there exists a solution $\tilde{T}_{S} \in\left[T_{S}, \hat{T}_{S}\right]$ to $\mathbf{W}\left(\tilde{T}_{S}, S_{0}^{f}, S_{0}^{c}\right)=0$.

We still need to check that for any $S_{0}^{c} \in\left(S_{0 S}^{c}, \hat{S}_{0 S}^{c}\right)$ we have $\mathbf{H}\left(\tilde{T}_{S}, S_{0}^{f}, S_{0}^{c}\right)>0$ where $\tilde{T}_{S} \in\left[T_{S}, \hat{T}_{S}\right]$ is solution to $\mathbf{W}\left(\tilde{T}_{S}, S_{0}^{f}, S_{0}^{c}\right)=0$; that is we need to check that $e^{\mathbf{H}\left(\tilde{T}_{S}, S_{0}^{f}, S_{0}^{c}\right)}=\mathbf{Z}\left(\tilde{T}_{S}, S_{0}^{f}\right)>1$. This last inequality holds indeed since (i) $\mathbf{Z}\left(T_{S}, S_{0}^{f}\right)=$ $e^{\mathbf{H}\left(T_{S}, S_{0}^{f}, S_{0 S}^{c}\right)}=1$ (see Remark 1) and (ii) $\frac{\partial \mathbf{Z}}{\partial \tilde{T}_{S}}>0$ and therefore $\mathbf{Z}\left(\tilde{T}_{S}, S_{0}^{f}\right)>\mathbf{Z}\left(T_{S}, S_{0}^{f}\right)>$ 1 for all $\tilde{T}_{S}>T_{S}$. Indeed one can check that $\frac{\partial \mathbf{Z}}{\partial \tilde{T}_{S}}>0$ : rewrite (A.17) as

$$
\mathbf{Z}\left(\tilde{T}_{S}, S_{0}^{f}\right)=\frac{\left(\hat{b}-k^{c}\right)}{\frac{r \beta S_{0}^{f}}{1-e^{-r T_{S}}}+2\left(\hat{b}-k^{f}\right)+\left(\alpha-\tau+k^{c}-2 k^{f}\right) \frac{-r \tilde{T}_{S}}{1-e^{-r T_{S}}}} .
$$

The denominator is an decreasing function of $\tilde{T}_{S}$ since both $\frac{r \beta S_{0}^{f}}{1-e^{-r \tilde{T}_{S}}}$ and $\frac{-r \tilde{T}_{S}}{1-e^{-r \tilde{T}_{S}}}$ are decreasing functions of $\tilde{T}_{S}$ and the term $\left(\alpha-\tau+k^{c}-2 k^{f}\right)>0$ from Assumption 2. This implies that $\frac{\partial \mathbf{Z}}{\partial \tilde{T}_{S}}>0$.

\section{A.8 Proof of Lemma 10}

If $\hat{\pi} \leq 0$, once the stock of the fringe is depleted (which occurs before depletion of the cartel's stock if $S_{0}^{c}>S_{0 S}^{c}$ ) the equilibrium is $\tilde{L}$ until exhaustion (from (14c)). Moreover, Lemma 2 implies that the initial regime is $S$. Finally, a transition from $F$ to $\tilde{L}$ is ruled out. We rule out as well a transition from $S$ to $F$ because $S_{0}^{c}>S_{0 S}^{c}$.

Indeed, suppose that, given $S_{0}^{f}$, we have for $S_{0}^{c}>S_{0 S}^{c}$ a sequence $S \rightarrow F$, i.e., from Lemma A.1, there exist $T_{S}$ and $T_{F}$ with $T_{S}<T_{F}$ that solve

$$
\begin{aligned}
r \beta S_{0}^{f}= & -\left(k^{f}-k^{c}\right)\left(r T_{S}-1+e^{-r T_{S}}\right)+\left(\hat{b}-k^{f}\right)\left(r T_{F}-1+e^{-r T_{F}}\right) \\
& +(\alpha-\tau-\hat{b}) r T_{F}, \\
r \beta S_{0}^{c}= & \left(k^{f}-k^{c}\right)\left(r T_{S}-1+e^{-r T_{S}}\right) .
\end{aligned}
$$

The value of $T_{S}$ is uniquely determined by $S_{0}^{c}$, moreover the value of $T_{F}$ and hence of the duration of the $F$ phase is a strictly increasing function of $S_{0}^{f}$. Now, given $S_{0}^{c}>$ $S_{0 S}^{c}$, consider the stock $\tilde{S}_{0}^{f}$ such that when the fringe owns a stock $\tilde{S}_{0}^{f}=\Phi^{-1}\left(S_{0}^{c}\right)$ (the function $\Phi^{-1}$ defined immediately after Lemma 3 ) and the cartel owns a stock $S_{0}^{c}$ we 
have the equilibrium consisting only of an $S$ phase: the duration of the $F$ phase is nil. However we know that since $S_{0}^{c}>S_{0 S}^{c}$ we have $\tilde{S}_{0}^{f}=\Phi^{-1}\left(S_{0}^{c}\right)>S_{0}^{f}=\Phi^{-1}\left(S_{0 S}^{c}\right)$ (since the function $\Phi^{-1}$ is strictly increasing) and therefore if the duration of the $F$ phase is positive under the stocks $S_{0}^{c}$ and $S_{0}^{f}$ it should be longer and therefore also positive, when the stock of the cartel is $S_{0}^{c}$ and the stock of the fringe $\tilde{S}_{0}^{f}>S_{0}^{f}$. Hence a contradiction of the fact that the duration of the phase is nil under the stocks $S_{0}^{c}$ and $\tilde{S}_{0}^{f}$, by definition of $\tilde{S}_{0}^{f}$.

This rules out a sequence $S \rightarrow F$ when $S_{0}^{c}>S_{0 S}^{c}$ and only leaves $S \rightarrow \tilde{L}$ as equilibrium sequence if $\hat{\pi} \leq 0$ and $S_{0}^{c}>S_{0 S}^{c}$.

\section{A.9 Proof of Proposition 2}

To prove part (i), note from (A.1b) that $\frac{d T_{S}}{d \sigma}=0$, from (12d) that $\frac{d q^{c}(0)}{d \sigma}=\frac{1}{\beta} d\left(\lambda^{f}-\lambda^{c}\right)$, and from (11a), (12b) and price continuity that $\lambda^{c}-\lambda^{f}=\left(k^{f}-k^{c}\right) e^{-r T_{S}}$. Combining these expressions yields $\frac{d q^{c}(0)}{d \sigma}=0$. To prove the increase in $q^{f}(0)$ upon a marginal increase in $\sigma$, we totally differentiate (A.1a)-(A.1b) and use $p(t)=k^{f}+\left(\hat{b}-k^{f}\right) e^{-r\left(T_{F}-t\right)}$ to obtain

$$
\frac{d p(0)}{d \sigma}=\frac{[\alpha-(b-\sigma)] e^{-r T_{F}}}{\left(\hat{b}-k^{f}\right) e^{-r T_{F}}-\left(\alpha-\tau-k^{f}\right)}<0,
$$

where the inequality follows from Assumption 1. As $\frac{d q^{c}(0)}{d \sigma}=0, \frac{d p(0)}{d \sigma}<0$ implies $\frac{d q^{f}(0)}{d \sigma}=$ $0>0$.

To prove part (ii), note from (A.3a) that $\frac{d \bar{T}_{S}}{d \sigma}=0$. Furthermore, by integrating (12c) and imposing the fringe's resource constraint, we obtain

$$
S_{0}^{f}=\int_{0}^{\bar{T}_{S}} q^{f}(t) d t=\frac{1}{\beta}\left(\alpha-\tau-2 k^{f}+k^{c}\right) \bar{T}_{S}+\frac{1 \lambda^{c}-2 \lambda^{f}}{r \beta}\left(e^{r \bar{T}_{S}}-1\right) .
$$

Combining these two results yields

$$
\frac{d \lambda^{c}}{d \sigma}=2 \frac{d \lambda^{f}}{d \sigma}
$$

Evaluating (12c) at $t=0$, taking the derivative with respect to $\sigma$ and imposing (A.22), we find $\frac{d q^{f}(0)}{d \sigma}=0$. To prove the decrease in $q^{c}(0)$ upon a marginal increase in $\sigma$ we totally differentiate (A.3a)-(A.4) to find

$$
\frac{d p(0)}{d \sigma}=\frac{\left[\alpha-(b-\sigma)-r\left(\bar{T}_{L}-\bar{T}_{C}\right)\left(\hat{b}-k^{c}\right)\right] e^{-r \bar{T}_{C}}}{\left.2 e^{r\left(\bar{T}_{L}-\bar{T}_{C}\right)}(b-\sigma-\alpha)-\left(1-e^{-r \bar{T}_{C}}\right) \hat{b}-k^{c}\right)}>0,
$$

where the inequality follows from noting that the denominator is negative due to As- 
sumption 1 , and by using (A.3c) to rewrite the term between brackets in the numerator as

$$
\left(\frac{1-r\left(\bar{T}_{L}-\bar{T}_{C}\right)}{e^{-r\left(\bar{T}_{L}-\bar{T}_{C}\right)}}-1\right)\left[2 \hat{b}-\alpha+\tau-k^{c}\right]<0,
$$

As $\frac{d q^{f}(0)}{d \sigma}=0, \frac{d p(0)}{d \sigma}>0$ implies $\frac{d q^{c}(0)}{d \sigma}=0<0$.

\section{A.10 Proof of Proposition 3}

For the equilibrium sequence $S \rightarrow F$, we totally differentiate (A.1a)-(A.1b) to get

$$
\begin{aligned}
\frac{d T_{F}}{d \sigma} & =\frac{1-e^{-r T_{F}}}{r\left[\left(\hat{b}-k^{f}\right) e^{-r T_{F}}-\left(\alpha-\tau-k^{f}\right)\right]}<0, \\
\frac{d T_{F}}{d \tau} & =-\frac{e^{-r T}-1+r T_{F}}{r\left[\left(\hat{b}-k^{f}\right) e^{-r T_{F}}-\left(\alpha-\tau-k^{f}\right)\right]}>0,
\end{aligned}
$$

where the inequalities follow from Assumption 1.

For the equilibrium sequence $S \rightarrow C \rightarrow \hat{L}$, we totally differentiate (A.3a)-(A.3c) to obtain

$$
\begin{aligned}
\frac{d \bar{T}_{L}}{d \sigma} & =-\frac{\left(1-e^{-r \bar{T}_{C}}\right)+e^{r\left(\bar{T}_{L}-\bar{T}_{C}\right)} 2 r\left(\bar{T}_{L}-\bar{T}_{C}\right)}{e^{r\left(\bar{T}_{L}-\bar{T}_{C}\right)} 2 r[\alpha-(b-\sigma)]+\left(1-e^{-r \bar{T}_{C}}\right) r\left(\hat{b}-k^{c}\right)}<0, \\
\frac{d \bar{T}_{L}}{d \tau} & =-\frac{\left(1-e^{-r \bar{T}_{C}}-e^{r\left(\bar{T}_{L}-\bar{T}_{C}\right)} r \bar{T}_{C}\right)}{e^{r\left(\bar{T}_{L}-\bar{T}_{C}\right)} 2 r[\alpha-(b-\sigma)]+\left(1-e^{-r \bar{T}_{C}}\right) r\left(\hat{b}-k^{c}\right)}>0, \\
\frac{d\left(\bar{T}_{L}-\bar{T}_{C}\right)}{d \sigma} & =\frac{\left(\alpha-k^{c}-\tau\right)}{\left.\left[\alpha-b 2+\sigma+k^{c}+\sigma+\tau\right)\right]^{2}}>0, \\
\frac{d\left(\bar{T}_{L}-\bar{T}_{C}\right)}{d \tau} & =\frac{[\alpha-(b-\sigma)]}{\left.\left[\alpha-b 2+\sigma+k^{c}+\sigma+\tau\right)\right]^{2}}>0,
\end{aligned}
$$

where the inequalities follow from Assumption 1.

\section{B Perfectly competitive equilibrium and first-best}

In the perfectly competitive equilibrium, the cartel takes the price path as given. Hence, the Hamiltonian associated with the cartel's problem reads

$$
\mathcal{H}^{c}=e^{-r t}\left(p(t)-k^{c}\right) q^{c}+\lambda^{c}\left[-q^{c}\right] .
$$


The necessary conditions include

$$
\begin{aligned}
p(t)=\alpha-\tau-\beta\left(q^{f}(t)+q^{c}(t)\right) & \leq k^{c}+\lambda^{c} e^{r t}, \\
{\left[k^{c}+\lambda^{c} e^{r t}-\alpha+\tau+\beta\left(q^{c}(t)+q^{c}(t)\right)\right] q^{c}(t) } & =0, \\
\dot{\lambda}^{c} & =0 .
\end{aligned}
$$

Along $C$ we have

$$
\begin{aligned}
p(t) & =\alpha-\tau-\beta q^{c}(t)=k^{f}+\lambda^{c} e^{r t}, \\
p(t) & =\alpha-\tau-\beta q^{c}(t) \leq k^{c}+\lambda^{f} e^{r t}, \\
q^{c}(t) & =\frac{1}{\beta}\left(\alpha-\tau-k^{c}-\lambda^{c} e^{r t}\right) .
\end{aligned}
$$

Throughout a phase of simultaneous use, (7a) and (A.28a) must hold with equality, which is not possible because $k^{f}>k^{c}$. Hence, simultaneous use cannot occur in a perfectly competitive equilibrium. A limit-pricing phase requires a constant price, which contradicts (A.28b). Furthermore, the equilibrium sequence $F \rightarrow C$ can be excluded, because, according to (7b), during the initial regime the net price $p-k^{f}$ grows at the rate of intrest, implying that the net price $p-k^{c}$ would grow at a rate lower than the rate of interest (because $k^{f}>k^{c}$ ). Hence, the cartel prefers current extraction over future extraction and will undercut the fringe's price. Therefore, the unique equilibrium sequence under perfect competition reads $C \rightarrow F$. Thus, by integrating (11c) and (A.29c) over time, denoting the transition time by $T_{1}$ and the depletion time by $T_{2}$, using the terminal condition $\lambda^{f}=\left(\hat{b}-k^{f}\right) e^{-r T_{2}}$, the price continuity condition $k^{c}+\lambda^{c} e^{r T_{1}}=$ $k^{f}+\lambda^{f} e^{r T_{1}}$, and the resource constraints of the cartel and the fringe, we find that the perfectly competitive equilibrium is described by

$$
\begin{aligned}
& r \beta S_{0}^{f}=\left(\hat{b}-k^{f}\right)\left(r\left(T_{2}-T_{1}\right)-1+e^{-r\left(T_{2}-T_{1}\right)}\right)+(\alpha-\tau-\hat{b}) r\left(T_{2}-T_{1}\right), \quad \text { (A.30a) } \\
& r \beta S_{0}^{c}=-\left(k^{f}-k^{c}\right)\left(1-e^{-r T_{1}}\right)-\left(\hat{b}-k^{f}\right)\left(e^{-r\left(T_{2}-T_{1}\right)}-e^{-r T_{2}}\right)+\left(\alpha-\tau-k^{c}\right) r T_{1} .
\end{aligned}
$$

In the perfectly competitive equilibrium described by (A.30a)-(A.30b) the only remaining market failure is the climate externality. Hence, the competitive equilibrium coincides with the first-best if carbon is priced at a rate equal to the SCC. This requires $\tau=\frac{\omega^{c} \psi}{r}$ during $C$ and $\tau=\frac{\omega^{f} \psi}{r}$ during $F$. By imposing these optimal tax rates together with $\sigma=0$, by integrating (11c) and (A.29c) over time, denoting the firstbest transition time by $T_{1}^{*}$ and the first-best depletion time by $T_{2}^{*}$, using the terminal condition $\lambda^{f}=\left(b-\frac{\omega^{f} \psi}{r}-k^{f}\right) e^{-r T_{2}}$, the social cost continuity condition $k^{c}+\lambda^{c} e^{r T_{1}^{*}}+\frac{\omega^{c} \psi}{r}=$ 
$k^{f}+\lambda^{f} e^{r T_{1}^{*}}+\frac{\omega^{f} \psi}{r}$, and the resource constraints of the cartel and the fringe, we find that the first-best is described by

$$
\begin{aligned}
r \beta S_{0}^{f}= & \left(b-\frac{\psi \omega^{f}}{r}-k^{f}\right)\left(r\left(T_{2}^{*}-T_{1}^{*}\right)-1+e^{-r\left(T_{2}^{*}-T_{1}^{*}\right)}\right)+(\alpha-b) r\left(T_{2}^{*}-T_{1}^{*}\right), \\
r \beta S_{0}^{c}= & -\left(k^{f}-k^{c}+\frac{\psi\left(\omega^{f}-\omega^{c}\right)}{r}\right)\left(1-e^{-r T_{1}^{*}}\right)+\left(\alpha-\frac{\psi \omega^{c}}{r}-k^{c}\right) r T_{1}^{*} \\
& -\left(b-\frac{\psi \omega^{f}}{r}-k^{f}\right)\left(e^{-r\left(T_{2}^{*}-T_{1}^{*}\right)}-e^{-r T_{2}^{*}}\right) .
\end{aligned}
$$

